\title{
AVATARES DEL VERSO ALEJANDRINO
}

Arturo Marasso dedica varias páginas de su estudio sobre el alejandrino ${ }^{1}$ a la cuestión de si este verso se formó amalgamando dos heptasílabos o si, por el contrario, el heptasílabo nació del desgajamiento del alejandrino en dos mitades. Dice que Nicolás Antonio veía el alejandrino como "endecha doble" ( $7+7$ sílabas), que otro tanto sentía fray Martín Sarmiento, y que incluso para Bello el alejandrino "no era un verso simple". Marasso, por su parte, se adhiere al parecer de Menéndez Pelayo: que en el proceso histórico "los metros compuestos han precedido a los simples" 2 . Por ejemplo - dice-, los heptasílabos de Sem Tob

Non ay lança que passe

todas las armaduras,

nin que tanto traspasse

como las escrituras,

están "pensados" en realidad como alejandrinos:

${ }^{1}$ Arturo Marasso, "Ensayo sobre el verso alejandrino", BAAL, 7 (1939), pp. 93-97 y $116-118$.

2 Tomás Navarro, Métrica española, Syracuse, N. Y., 1956, § 46, después de decir que "un dístico heptasílabo es análogo a un alejandrino con rima interior", añade: "[no] es seguro que el alejandrino deba considerarse como suma de dos heptasílabos"; y observa que el heptasílabo "figura entre los metros más antiguos en francés, provenzal e italiano, de manera que [esta] antigüedad impide considerarlo como resultado de la separación de los hemistiquios del alejandrino". 
Non ay lança que passe todas las armaduras, nin que tanto traspasse como las escrituras,

dado que "Non ay lança que passe" carece de "unidad de pensamiento".

Este argumento merece comentario. Lo que hace que unas pocas palabras sean verso no es la sintaxis, sino la rima. Marasso hubiera podido añadir que "una de las copias antiguas de los Proverbios de Sem Tob" está escrita justamente en versos largos (cf. Navarro, § 46); pero desde mucho antes de Sem Tob el heptasílabo se había independizado ya del alejandrino, como se ve en la Historia troyana en prosa y verso ( ca. 1270 según Menéndez Pidal). La poesía IV consta de alejandrinos (cuaderna vía), pero la $\mathrm{V}$ está en heptasílabos hechos y derechos:

$$
\begin{aligned}
& \text { ¡Ay Priamo, mi padre, } \\
& \text { tan mal que lo feziestes! } \\
& \text { ¡Ecuba, la mi madre, } \\
& \text { por mi mal me pariestes! }
\end{aligned}
$$

Por otra parte, la "unidad de pensamiento" bien puede no caber en un solo verso: "Por nasçer en espino non val la rosa cierto" no tiene sentido sin el adverbio "menos" con que empieza el verso siguiente. He aquí un ejemplo clarísimo:

Si mi razón es bona, non sea despreçiada porque la diz persona rafez; que mucha espada de fyno azero sano sab de rrota vaýna salir, e del gusano se faz la seda fina.

En ningún verso hay "unidad de pensamiento". En todos hay encabalgamiento: despreciada|porque, persona|rafez, espada|de acero, sab|salir ('suele salir'). Berceo se hubiera quedado espantado ante estos versos, tan verdaderamente "modernos".

También en la Historia troyana hay encabalgamientos. Leemos en una cuarteta que el infante Troílo está decidido a meterse "en logar do 'l matassen", pero el sujeto de "matassen", que es "los griegos", está al comienzo de la cuarteta siguiente.

Así, pues, lo que cuenta es la rima. Bien puede ser que algunos de los "refranes que dizen las viejas tras el huego", por ejemplo "Tras pared ni tras seto no digas tu secreto", sean -como cree MARASSO, pp. 96-97, siguiendo a Jeanroy- "versos suel- 
tos de poesías olvidadas", pero no cabe duda de que la rima nos obliga a ver tales refranes como pareados de heptasílabos ${ }^{3}$. Y el hermoso villancico “¿Con qué la lavaré...?” puede imprimirse lo mismo en cuartetas de heptasílabos que en dísticos alejandrinos:

¿Con qué la lavaré la flor de la mi cara?

¿Con qué la lavaré, que vivo mal penada?

Lávanse las casadas con agua de limones; lávome yo, cuitada, con ansias y dolores ${ }^{4}$.

La expresión gráfica de los versos -la tipografía - tiene su papel en todo esto. Cada unidad rítmica, resaltada a menudo por la rima, pide renglón aparte. Pero no es conditio sine qua non. De hecho, da lo mismo sentir los Proverbios de Sem Tob y el “¿Con qué la lavaré...?” como heptasílabos que como alejandrinos con rima interna (consonante o asonante).

No estará de más situar esto en un cuadro más amplio. Lo que ha sucedido con el heptasílabo respecto del alejandrino es análogo a lo sucedido con el octosílabo respecto del antiguo verso juglaresco, con el tetrasílabo ("pie quebrado") respecto del octosílabo y con el hexasílabo respecto del verso de arte mayor.

En 1815 imprimió Jakob Grimm los romances viejos en "dieciseisílabos", considerando que "el género épico exige verso largo”, y Menéndez Pidal siguió su ejemplo, -decisión muy respetable; pero la verdad es que da lo mismo. O casi lo mismo. Si oigo recitar "Rey don Sancho, rey don Sancho", no me preocupa lo más mínimo si el recitante está leyendo octosílabos o dieciseisílabos; pero cuando leo romances prefiero, con mucho, los versos cortos. Es la forma que han tenido desde "Estáse la gentil dama" ( $c a .1421)$ hasta la fecha. (A nadie se le ocurriría imprimir en dieciseisílabos el "Manzanares, Manzanares" de Góngora, cuyo primer verso nos remite a inicios de romances viejos como "Rey don Sancho, rey don Sancho" o "Durandarte, Durandarte".

El octosílabo, engendrado por el verso largo heroico, engendró a su vez al tetrasílabo. La primera de las poesías de la Historia troyana está hecha en sextillas octosilábicas $a a b / c c b$ :

${ }^{3}$ Dice Marasso que la "rima interna" (seto) "no destruye el verso sino que coadyuva a su unidad esencial". Todo depende de lo que sienta el lector.

${ }^{4}$ Margit Frenk, Corpus de la antigua lírica popular hispánica, núm. 589, lo imprime en heptasílabos. 
¡Ay, señor! ¡Qué companero, qué leal e qué guerrero que he yo en vos perdudo! ¿Qué ardit e qué esforçado, qué franco e qué enseñado, qué manso e qué sesudo!

El esquema de la segunda poesía parece muy distinto:

\author{
¡Ay qué quexa, \\ qué quebranto, \\ que aquexa \\ a mí tanto, \\ que non podría más syn falla! \\ ¡Ay qué coyta \\ mal apresa \\ que m'acoyta, \\ que me pesa \\ de aquesta negra batalla!,
}

pero si se amalgaman dos a dos los tetrasílabos ("¡Ay qué quexa, qué quebranto!”) resulta una sextilla octosilábica de la misma hechura que la anterior. Observemos que el tetrasílabo no se ha desgajado por completo del octosílabo, pues la bipartición de éste produce a veces hemistiquios pentasilábicos, como "AAy qué grand mal!" (la irregularidad se remedia leyendo entero el octosílabo: "¡Ay qué grand mal passaredes!”).

Algo semejante sucede en el poema ;Ay, Iherusalem!, contemporáneo de la Historia troyana en prosa y verso ${ }^{5}$ : sus hexasílabos no se han desgajado completamente del dodecasílabo empleado - aunque sin mucho rigor- en la mayor parte del poema, que resulta ser, por cierto, el documento más antiguo del verso "de arte mayor". Está hecho en estrofas como la siguiente:

${ }^{5}$ Véase el texto en NRFH, 14 (1960), pp. 244-246, y el comentario de Eugenio Asensio, “iAy, Iherusalem!, planto narrativo del siglo xiI", ibid., pp. $251-270$. 
Estos moros perros a la casa santa siete años e medio la tienen çercada; non dubdan morir por la conquerir (en Iherusalem).

Dos dodecasílabos y dos hexasílabos. Pero en un verso como "Grandes afincanças ponen con sus lanças" el dodecasílabo mismo se convierte en un par de hexasílabos. Y esto sucede varias veces. Los dodecasílabos

mandan dar pregones por la christiandad, alçan sus pendones, llaman Trinidad

son en realidad una cuarteta de hexasílabos, con rimas consonantes $a b a b$. De la misma manera, los versos

De las vestimentas fazían cubiertas, del sepulcro santo fazían establo

son hexasílabos con rima asonante $a a b b$. O sea que $i A y$, Iherusalem! es también el testimonio más antiguo de versos como "Señor Gómez Arias, / doléos de mí", o "Siete días anduve / que no comí pane" (o "Hermana Marica, / mañana que es fiesta...").

Por ser ¡Ay, Iherusalem! un documento tan arcaico de poesía lírica, todas sus características merecen atención. Predominan las rimas consonantes, pero hay muchas asonantes y abundan las equivalencias acústicas (como patriarca/carta, sangre/ fanbre y arte/Acre). Evidentemente, el "arte poética" del siglo XIII permitía todas estas libertades. Predominan los versos dodecasílabos (el futuro "arte mayor"), pero a veces los hay de 13 sílabas, porque alguno de los hemistiquios tiene 7 en vez de 6, y hasta hay algunos perfectamente alejandrinos:

llorar noches e días, gemir e non dormir... tienen a los abades en cepo de maderos...

Por lo visto, el poeta guardaba aún en la cabeza el recuerdo de la cuaderna vía. ¿Y no será el verso de arte mayor un vástago del alejandrino?

Me he extendido demasiado, pero me pareció útil lanzar unas cuantas observaciones sobre "teoría y praxis" del verso. De hecho, lo decisivo es el uso. 
Henríquez Ureña distingue cuatro etapas en "la historia del alejandrino": 1) su prominencia en los siglos del mester de clerecía; 2) su eclipse en los siglos XV a XVIII; 3) su resurrección "a plena luz" en el último cuarto del siglo XviII, y 4) su "nuevo esplendor", a partir de los románticos. Y subdivide esta cuarta etapa en tres fases: $a$ ) de Iriarte a Zorrilla; $b$ ) de Zorrilla (1838) en adelante, y $c$ ) de Rubén Darío (1883) en adelante . $^{6}$

En cuanto a la primera de las cuatro etapas, no sé si alguien puede añadir algo a lo que se ha dicho. Yo, desde luego, no. Pero vale la pena reflexionar sobre la enormidad del olvido posterior. Fue un eclipse total. En la segunda mitad del siglo XVI no se conocía ni siquiera el nombre de Gonzalo de Berceo. Parece que el único que se acuerda de la cuaderna vía es el erudito anticuario Argote de Molina, el cual, a propósito del dístico final de uno de los enxiemplos del Conde Lucanor, hace el siguiente comentario:

Usávase en tiempos [de don Juan Manuel] en España este género de verso largo, que es de doze, o de treze, y aun de catorze síllabas, porque hasta esto se estiende su licencia. Creo lo tomaron nuestros poetas de la poesía francesa [...]. En algunos romances antiguos ytalianos y en poetas heroycos se hallan [también] estos versos [...]. Pudo ser que todos lo tomassen de la poesía bárbara de los árabes [...]. Los ingenios de aora, como son algo coléricos, no sufren la lerdez y espacio de esta compostura por parescerles muy flegmática y de poco donayre y arte, aunque en los antiguos autores da algún contento, y deve ser por la antigüedad y estrañeza de la lengua más que por el artificio ${ }^{7}$.

Es muy explicable que Argote diga que el alejandrino - no llamado así por él, sino "verso largo" o "verso grande"- está hecho "de 12, de 13, y aun de 14 sílabas", porque los hay así en las cuatro cuartetas del Poema de Fernán González que cita. (Él guarda en su "museo" ese arcaico manuscrito.) Lo curioso es que ponga el origen del alejandrino en "la poesía bárbara de los

6 Pedro Henríquez Ureña, "Sobre la historia del alejandrino", RFH, 8 (1946), pp. 1-11. Y añade: "Quizá haya que contar, si la situación actual no se modifica, una nueva fase $[d]$ : desde alrededor de 1920 los poetas emplean poco el alejandrino, y bien podría eclipsarse de nuevo".

7 Gonzalo Argote de Molina, Discurso sobre la poesía castellana, ed. E. F. Tiscornia, Madrid, 1926, pp. 35-39; y véase el comentario de Tiscornia, pp. $90-100$. 
árabes". Dice también: "Quien quisiere saber la cuenta y razón deste verso lea la Grammática española del maestro Antonio de Lebrixa, donde en particular se tracta", lo cual es falso. No podían ser más claras las señales de ignorancia en un varón tan erudito como Argote de Molina.

Probablemente no conocía Argote en 1575 (fecha de su edición del Conde Lucanor) las siete primorosas estancias de "versos franceses" que once años antes había incluido Gaspar Gil Polo en su Diana enamorada (NBAE, t. 7, p. 385):

De flores matizado se vista el verde prado, retumbe el hueco bosque de voces deleitosas; olor tengan más fino las coloradas rosas, floridos ramos mueva el viento sosegado; el río apresurado sus aguas acreciente;

y pues tan libre queda la fatigada gente del congojoso llanto,

moved, hermosas ninfas, regocijado canto.

Si las hubiera conocido, seguramente no habría dicho que una composición en alejandrinos resulta "muy flegmática y de poco donayre y arte". Los alejandrinos de Gil Polo tienen donaire y arte. Cervantes debe de haber pensado en ellos cuando hizo decir al Cura: "[La Diana de Alonso Pérez] acompañe y acreciente el número de los condenados al corral, y la de Gil Polo se guarde como si fuera del mesmo Apolo”.

Sigue, en orden cronológico, el soneto que "en nombre de Heraclio" se lee en los preliminares de la Comedia intitulada Doleria de Pedro Hurtado de la Vera (Amberes, 1572):

Preguntadme quién soy, no oso publicallo; del poco que merezco nasce este temor; podría ser también de ser nuevo pintor: vos responderéis, pintura, lo que callo...

El verdadero nombre del autor era Pedro de Faría, como se descubre en un complicado acróstico. Tengo para mí que era un judío de origen español establecido en Flandes de largo tiempo atrás, y sin contacto con los españoles de Amberes. No da señas de haber leído siquiera a Garcilaso; los versos que leía eran seguramente franceses. (Su otro libro, Historia del príncipe 
Erasto, se imprimió también en Amberes, en 1573.) La Doleria tuvo otras dos ediciones, pero no en España, sino de nuevo en Amberes en 1595 y en París en 1614. En su descripción de la primera edición, menciona Gallardo ese "maldito soneto, $\mathrm{cu}-$ yos versos apenas constan"; y en la descripción de la $3^{\text {a }}$ ed. lo llama "un cruel soneto, de versos entre castellanos y franceses" -juicio que no tiene vuelta de hoja.

Para sustentar su idea de que el "verso largo" del Fernán González se remonta a ciertas poesías árabes "bárbaras", Argote de Molina pone como ejemplo uno de los varios "cantares lastimeros" que personalmente les oyó "a los moriscos del reyno de Granada sobre la pérdida de su tierra”. Da el texto árabe y en seguida lo traduce en "versos largos". Pero antes ha puesto otro ejemplo: unos "versos turquescos amorosos dedicados a la diosa de los amores que los turcos en su lengua llaman Asich". También aquí da el texto turco y luego lo traduce en la misma forma. La traducción del cantar de los moriscos está en español normal del siglo Xvi ("Alhambra amorosa, lloran tus castillos..."), mientras que la de los versos turquescos está en español arcaico ("mis cueytas", "esta afruenta", “¿qué fare?", "al Criador acorro en esta sobrevienta") ${ }^{9}$. Las dos traducciones contienen versos de 12, 13 y aun 14 sílabas; de estos últimos, sólo hay dos: "Guadix tie-

${ }^{8}$ La Doleria está en NBAE, t. 14, pp. 312-388. Gallardo (Ensayo, t. 3, cols. 252-254) redactó las dos papeletas en momentos distintos. En la muy breve descripción de la ed. de 1572 copia sólo el primer verso del soneto; en la otra, más detallada, copia el primer cuarteto y dice, erróneamente, que el soneto no estaba en la 1a ed., sino que es "añadidura de la edición de París". Siempre alerta, Gallardo subraya la palabra del en "del poco que merezco", obvio galicismo ("du peu que je mérite"). Sólo siete de los 14 versos son alejandrinos ortodoxos. Cf. NAvARro, $§ 127$ y nota. Tengo noticia de un estudio que no he leído: Narciso Alonso Cortés, "El autor de la comedia Doleria", en sus Anotaciones literarias, Valladolid, 1922.

${ }^{9}$ Estos arcaísmos desconciertan no poco a Tiscornia. Aparte de que Argote no sabía turco - dice-, la "composición" de los versos castellanos "es muy anterior a los tiempos del erudito sevillano". Es raro que no se haya dado cuenta de que es una ocurrencia del erudito. Los versos turquescos, como él mismo dice, están tomados del libro de Bartolomé Georgiewitz, De Turcarum ritu ac coremoniis, publicado a mediados del siglo XVI y traducido muy pronto al italiano. (Es una de las fuentes del Viaje de Turquía de Andrés Laguna: cf. M. BAtaillon, Erasmo y España, 2a ed., pp. 672-673.) Georgiewitz publica el texto turco y lo traduce al latín. Pero la "ocurrencia" es una trampa: Argote ha querido que esos versos en fabla confirmen la gran antigüedad de los versos largos. 
ne mis hijos, Gibraltar mi mujer" en la versión del árabe, y “¿Qué faré que non puedo vencerme en esta afruenta?" en la del turco.

Al comienzo de los Dos tratados, del Papa y de la Missa (Londres, 1588) de Cipriano de Valera, desarraigado como el autor de la Doleria (era un franciscano que en 1555 había huido de su convento sevillano para pasarse al protestantismo), hay dos sonetos; el primero comienza "Vos, que hijos de Tros, nefando arrebatar...", y el otro "Iberia, este Ibero aquí ha trabajado..."; de ellos dice Gallardo: "Éstos ni son sonetos ni versos". Pero, leídos con un poco de buena voluntad, sí que son versos, y alejandrinos; basta hacer hiatos sistemáticamente ${ }^{10}$.

El primer preceptista que trata del alejandrino es Luis Alfonso de Carvallo en su Cisne de Apolo, publicado en Madrid en 1602. Lo llama "verso francés" 11 , dice que se compone de dos heptasílabos "ayuntados en uno" y cita el primer verso de las estancias de Gil Polo ("Ésse me parece que calça catorze puntos", comenta Zoylo, o sea: ¡Uy, qué pie tan largo!). En otro pasaje del libro añade Carvallo que con "el verso francés y su quebrado" -o sea el heptasílabo- se pueden hacer estancias de canción; esta vez pone un ejemplo propio - y bastante mediocrecon una disposición casi igual a la de los versos de Gil Polo: "Amar sin esperança lo juzgo a gran locura..."12.

En la "segunda parte" de las Flores de poetas ilustres, compilada en 1611 por Juan Antonio Calderón, está el excepcional "Soneto en alejandrinos" de Pedro de Jesús, nombre que adoptó Pedro Espinosa cuando le dio por hacerse ermitaño. Vale la pena copiarlo:

${ }^{10}$ Gallardo, Ensayo, t. 4, col. 859. Cf. también Navarro, $\$ 137$ y nota. (Si Gallardo dice que "no son sonetos" es a causa del extraño orden que guardan los consonantes de los cuartetos: $A A B B-A A B B$.)

11 Diego de Nájera y Cegrí llama "troba franzesa" un poema hecho por él en eneasílabos, metro insignemente raro: cf. A. R. MoÑino y M. BREY, Catálogo de los mss. de la H.S.A., t. 2, p. 302.

12 Luis Alfonso de Carvallo, Cisne de Apolo, ed. A. Porqueras Mayo, Madrid, 1958, pp. 192 y 261. También FiLIPE Nunes menciona los "versos francezes" (Arte poética e da pintura, Lisboa, 1615, fol. 5) y copia el ejemplo de Carvallo. (Nunes, lector sagaz, es el único preceptista del siglo de oro que presta atención a las gracias métricas de Cervantes: los "versos troncados", fol. 6: "Si de llegarte a los bue-...”, y el ovillejo, fol. 17: “¿Quién menoscaba mis bienes?") 
Como el triste piloto que por el mar incierto se ve, con turbios ojos, sujeto de la pena sobre las corvas olas que, vomitando arena, lo tienen de la espuma salpicado y cubierto,

cuando sin esperanza, de espanto medio muerto, ve el fuego de Santelmo lucir sobre la antena $y$, adorando su lumbre, de gozo el alma llena, halla su nao cascada surgida en dulce puerto, así yo el mar sulcaba de penas y de enojos, y con tormenta fiera, ya de las aguas hondas medio cubierto estaba, la fuerza y luz perdida, cuando miré la lumbre ¡oh Virgen! de tus ojos, con cuyos resplandores quietándose las ondas, llegué al dichoso puerto donde escapé la vida.

Este soneto quedó hundido en la oscuridad hasta $1896^{13}$, de manera que no pudo conocerlo el enciclopédico Juan Caramuel y Lobkowitz, que en su Rhythmica (Roma, 1665), al tratar de los "dodecasílabos", como él llama a los alejandrinos, pone como ejemplo un soneto en francés: el epitafio de Lope de Vega por "Madame Argenis"14.

Menéndez Pelayo, cuyo aborrecimiento del alejandrino comentaré más adelante, dice del soneto de Espinosa: "Me permitiréis que le consigne [= reproduzca] aquí, para que si tales sonetos llegan a aclimatarse, que lo dudo, cuenten a lo menos con algún antecedente en nuestra flora poética nacional”. La influencia de una flora gabacha es innecesaria. ( $¡ Y$ esto se escribió en 1907 ! $)^{15}$.

${ }^{13}$ Lo publicó Francisco Rodríguez Marín en su ed. de la Segunda parte de las Flores de poetas ilustres de España, Sevilla, 1896, p. 245. (El manuscrito se intitula simplemente Flores de poetas.)

${ }^{14}$ Está en la Fama pósthuma: A la vida y muerte de... Lope de Vega Carpio, Madrid, 1636, fol. 132r. Sobre las doctrinas métricas de Caramuel puede verse A. Alatorre, "Avatares barrocos del romance”, NRFH, 26 (1977), pp. 353-359.

15 Marcelino Menéndez Pelayo, Estudios y discursos de crítica histórica y literaria, ed. de Madrid, 1942, t. 5, p. 46. Obviamente, esta estrechez de criterio o parti-pris le impidió a don Marcelino leer de veras el soneto. Tal vez se limitó a pasar la vista por él. Y el soneto es muy bueno, original por su metro, desde luego, pero también por la estructura del discurso: los encabalgamientos son muy sabios, y el soneto todo constituye una oración continua: "Así como el piloto de un barco destrozado por la tempestad, cuando ya desespera de salvarse, ve de pronto el tranquilizador fuego de Santelmo, así naufragaba yo en medio de las tormentas mundanas cuando tú ¡oh Virgen! 
Si los alejandrinos de Espinosa son una rareza, resultan en cambio muy naturales los de Ambrosio de Salazar, cuya infatigable actividad se desarrolló toda en Francia. He aquí dos dystiques de la "Vida del autor" antepuesta al Espexo general de la gramática (Rouen, 1614):

...Y después, no sabiendo lo que de mí sería, me vine aquí a Rouán por una fantasía,

do he enseñado a muchos la lengua de Castilla, y me entretengo entre ellos por grande maravilla.

También Góngora hizo alejandrinos. Si nadie parece haberlo notado es seguramente a causa de la tipografía. Me refiero a la hermosa canción "Vuelas, oh tortolilla...", escrita en 1602 y publicada en 1605 en las Flores de Espinosa, cuyas estrofas, impresas como ocho heptasílabos (el 1, el 4 y el 7 anómalamente sueltos) y un endecasílabo al final, debieran en realidad imprimirse así:

Vuelas, oh tortolilla, y al tierno esposo dejas en soledad y quejas.

Vuelves después gimiendo; recíbete arrullando, lasciva tú si él blando.

Dichosa tú mil veces, que con el pico haces dulces guerras de amor y dulces paces...

En efecto, los tres heptasílabos sueltos no son sino los primeros hemistiquios de sendos alejandrinos.

"Esta dulcísima canción - dice Salcedo Coronel en su edición de Góngora- merece no poca estimación; es una de las más numerosas y suaves que se pueden hallar en nuestra lengua, ni sé que ninguna de las italianas la exceda”. Sedano, que la incluye en su Parnaso (tomo 9, 1778, pp. 368-370), la ve como "una especie de anacreóntica de las que con más ternura de argumento y suavidad de estilo pudo producir [Góngora] cuando quiso seguir el camino llano y anchuroso de la pureza del lenguage, y por esta parte comparable a las más dulces odas

me hiciste ver tu luz". A Espinosa le gustaba experimentar e innovar: es uno de los inventores (cuando no el inventor) del metro de silva. Cf. A. AlatoRRE, "Quevedo: de la silva al ovillejo", Homenaje a Eugenio Asensio, Madrid, 1988, pp. 20-22. 
de Villegas, Medrano, Liñán y Francisco de la Torre" (ibid., p. xlvi) ${ }^{16}$. Navarro no la ve como anacreóntica, sino como endecha "en estrofas abbcddfF" (endecha, a decir verdad, sin mucho que ver con las verdaderas endechas, que son romancillos).

Con este agrupamiento de versos de 14-7, 14-7 y 14-11 sílabas, Góngora parece haber querido emular los "versos franceses" de Gil Polo, cuya Diana era una de las cumbres indiscutidas de "lo bucólico"; pero redujo el tamaño de las estancias, haciendo, en consecuencia, más compacto el discurso poético, más quintaesenciado. El tema no tiene originalidad alguna (era uno de los lugares comunes de la lírica pastoril, y Lope de Vega lo usó mucho); pero también del tema ha sacado Góngora una "quintaesencia”. (El endecasílabo final de la primera estrofa es, como observó Gallardo, un homenaje a Tasso: dolci guerre d'amor e dolci paci > "dulces guerras de amor y dulces paces").

En su edición de Canciones y otros poemas en arte mayor de Góngora (1990), José María Micó dice de "Vuelas, oh tortolilla": "Es una estrofa muy peculiar, de la que no conozco otros ejemplos: tres versos sueltos $\left(1^{\circ}, 4^{\circ}\right.$ y $\left.7^{\circ}\right)$ seguidos de sendos pareados". En realidad sí se conocen otros ejemplos: las dos imitaciones que se recogen en el Cancionero de 1628: la "Canción a un naufragio" de García de Porras: "Rompe segura nave el campo christalino, / y con alas de lino..." (ed. Blecua, pp. 483-484) y un anónimo "Entierro de Christo en Çaragoça": "Del difunto monarca del claro firmamento / el cadáver sangriento..." (ibid., pp. 372-374). Nada del otro mundo, pero al menos acrecientan un poco el número de alejandrinos hechos en el siglo de oro.

Bien visto, ya en la composición "Moriste, ninfa bella...", de 1594, había hecho Góngora unos alejandrinos "tipográficamente disfrazados" de endecha, como se ve si los imprimimos así.

Moriste, ninfa bella, en edad floreciente;

que la muerte entre flores se esconde, cual serpiente...

Son 42 alejandrinos con una sola rima consonante ${ }^{17}$.

${ }^{16}$ El juicio de Sedano, como es natural, exhala un fuerte tufo de "estética neoclásica": distinción entre un Góngora tenebroso y un Góngora no sólo "accesible", sino leído y celebrado. Son, por otra parte, los tiempos de la proliferación de "anacreónticas". Meléndez Valdés no tardará en hacer su aparición.

17 Creo que Góngora fue el primero que hizo romances en heptasílabos, pues el romancillo "De tus rubios cabellos, / Dórida ingrata mía...", 
(Otro poema gongorino que tiene que ver con la tipografía es "Mátanme los celos de aquel andaluz", incluido por Millé entre las "composiciones de arte mayor", pero mal, pues no son sino seguidillas ${ }^{18}$ impresas en versos largos. Es caso contrario al de "Vuelas, oh tortolilla" y "Moriste, ninfa bella".)

A diferencia de los de Góngora, ignorados por escondidos, los alejandrinos de Alonso Carrillo (combinados con heptasílabos) son bien conocidos. Sirven de "argumento" al Libro de la erudición poética de su hermano Luis. En la primera edición, de 1611, los alejandrinos se imprimen como versos largos, mientras que en la segunda, de 1613, se fragmentan en heptasílabos: lo que era primero una pequeña "silva" de alejandrinos y endecasílabos (sueltos todos) quedó convertido en otra de endecasílabos y heptasílabos (sueltos también, por supuesto) ${ }^{19}$.

Después de los de Carrillo (1611) y los de Ambrosio de Salazar (1614), los alejandrinos de lengua española sufren el conocido eclipse total ${ }^{20}$ (y larguísimo: de un siglo y dos tercios). Pero cuando reaparecen, en 1774, lo hacen de manera muy espectacular. En ese año se imprimió en Sevilla la primera entrega de las Poesías filosóficas en verso pentámetro, compuestas por "el Poeta Filósofo". Siempre se supo que éste era un clérigo radicado en Sevilla, de nombre Cándido María Trigueros, muy "amigo de novedades", y con no pocas puntas de herejía. A causa de tan largo eclipse, el alejandrino era totalmente desconocido en

atribuido a Gutierre de Cetina, es a todas luces espurio. Los romances "Sobre unas altas rocas" (1600), "En tanto que mis vacas" (1601) y "Celosa estás, la niña" (1608), son heptasílabos, pero sus rimas son asonantes; por otra parte, "Tendiendo sus blancos paños" (1591) y "Despuntado he mil agujas" (1596) tienen una sola rima consonante (de carácter grotesco: respectivamente -etey -ote), pero no son heptasílabos.

${ }^{18}$ Las únicas que hizo Góngora. ¿Serán parodia de las muchas que hizo Lope de Vega?

19 "La corrección - dice Marasso, p. 79- es probablemente desacertada; [el autor] se propuso escribir versos de carácter epigramático, pues no llevan rima, y combinó endecasílabos con alejandrinos, en esos años, por 1610, en que más de un joven pensaría en la renovación métrica”. Bien dicho, pero esa renovación estaba ya en marcha, testigo Góngora.

20 "Deben añadirse - dice NAvARro, § 198- los alejandrinos que se hallan en los estribillos de dos villancicos de sor Juana Inés de Cruz" (ed. A. Méndez Plancarte, t. 2, núms. 219 y 243). Yo no creo que deban añadirse. No cuentan: son alejandrinos muy accidentales, revueltos además con dodecasílabos de 7-5 sílabas (metro de seguidillas). 
español ${ }^{21}$. Los lectores cultos estaban bien familiarizados con el alexandrin francés, pero hasta ellos ignoraban que hubiera alejandrinos españoles. Lo notable de Trigueros es su categórica afirmación de ser el creador de un verso nuevo. Sabe que algunos dirán: "¡Bah, otra moda francesa que se nos cuela en España!”; pero no es así: ese verso lo ha discurrido él, tomando como dechado el pentámetro latino; por eso lo bautiza como pentámetro español ${ }^{22}$. Está convencido de que tanto la materia como la forma van a toparse con resistencias, pues "este género de poesía [filosófica] es nuevo, y lo es también el mecanismo del verso". Y se le ocurre una comparación: "Quando pasó de Italia a España el verso endecasílabo, creo que tendría sus opositores”, pero al fin triunfó. Así pues, ¿por qué no esperar lo mismo de este invento suyo, que tiene "el mérito de ser más magestuoso" que el mismísimo endecasílabo? Y termina: "Sea como fuere, yo soy el fundador de esta aldeilla; como tal le he prescrito sus leyes municipales".

El poema inicial, "El Hombre", es paráfrasis del Essay on Man del nada católico Alexander Pope, que después de ser admirado en Europa durante cuarenta años se dejaba por fin escuchar en España ${ }^{23}$. Comienza así:

Dime, sublime Pope, tú, reflexivo genio, que unes con arte tanto el juicio y el ingenio,

britano Horacio, dime, tú que con tal cuidado, tú que con tal acierto al Hombre has estudiado...

${ }^{21}$ Gabriel Álvarez de Toledo Pellicer y de Tobar (1662-1714), nieto del famoso Josef Pellicer y de Tobar, y pedante como él, dedicó "Au Roi Catholique" (o sea al recién instalado Felipe V) un soneto en alejandrinos, pero en francés: "Héros en qui le Ciel a fait un assemblage..." (Obras pósthumas poéticas, Madrid, 1744, pp. 14-15).

${ }^{22}$ Francisco Aguilar Piñal, Un escritor ilustrado: Cándido María Trigueros, Madrid, 1987, dedica a las composiciones del Poeta Filósofo las pp. 135-152. El proyecto de Trigueros "comprendía más de veinte largos poemas, de los que sólo se publicaron trece". Aguilar Piñal ha tenido la paciencia de contar los alejandrinos que hay en esos trece poemas: jsuman 17824 !, y eso que aquí no entran dos que están fuera de la serie: San Felipe Neri al clero (1775) y El viaje al cielo (1777). Aguilar Piñal, cuyo libro me ha servido mucho, parece olvidar la traducción de los libros I-III y parte del IV de la Eneida, hecha asimismo en alejandrinos: véase MenÉndez Pelayo, Bibliografía hispano-latina clásica, ed. de 1952, t. 8, pp. 379-380.

${ }^{23}$ MenÉndez Pelayo, Estudios y discursos..., t. 6, pp. 26-29, se ocupa de dos traducciones más tardías: la de Antonio Fernández Palazuelos (¡un jesuita!) y la del ecuatoriano José Joaquín Olmedo. 
En los peliminares del poema IV ("La moderación") hay una "Advertencia del editor [Juan Nepomuceno González de León] al público sobre el género de versos de estos poemas". Cuenta que "un sabio con mucha razón famoso" le mandó una carta que decía que versos como ésos se habían hecho en la Edad Media, según constaba en cierto manuscrito conservado en la gran biblioteca del Escorial. El editor le mostró al autor la carta del "sabio famoso" (que resultó ser el erudito Francisco Pérez Bayer) y Trigueros replicó:

En efecto, los versos [de cuaderna vía] son... del mismo metro que yo, inadvertidamente, proponía como invento nuevo, mas quizá no dexaré por eso de ser inventor de los pentámetros castellanos tales como los uso ... [Me alegro, sí, de saber que ya existían en español y que no son imitación francesa]. Yo, entretanto, ni los he imitado de nuestros antiguos ni los he mendigado de nuestros vecinos. Quando estudiaba la lengua latina, sin conocer ni nuestra poesía ni nuestros poetas, y sin saber otra lengua que muy mal la de mi patria, traduxe algunas odas de Oracio en este género de versos, los quales hice a imitación de los pentámetros latinos.

Trigueros estaba resuelto a no dar su brazo a torcer.

En 1775, apenas un año después de iniciada la publicación de las Poesías filosóficas, se imprimieron póstumamente las Memorias para la historia de la poesía y poetas españoles de fray Martín Sarmiento $(\dagger 1771)$, el cual dedica no poca atención a Berceo, ese poeta arcaico y desconocido, y por principio de cuentas se ve obligado a explicar en qué metro escribió sus obras:

A estos versos llamó el Cysne de Apolo [o sea Carvallo] versos franceses, porque los usaron y usan; y los franceses los llaman alejandrinos... Yo llamara castellanos a estos versos..., pues las poesías antiquísimas que nos han quedado están en este metro...; y sobre todo se debían llamar versos de Berceo.

Esto, añadido al señalamiento de Pérez Bayer, causó fisuras en la seguridad de Trigueros. Dejó de proclamarse inventor, pero ahora quiso hacerse pasar por un erudito al corriente de las cosas: "Sé muy bien dónde vio el señor Pérez Bayer o dónde tomó la noticia hoy tan común entre los eruditos, quanto saben que desde el tiempo del Cid hasta el de don Juan II [!] no se poetizaba en otros versos". Algo de gloria le queda, sin embargo: la novedad de esos versos hoy, en la república literaria 
actual; prueba de ello es el escándalo que se ha suscitado. Lo dice así en el prólogo de El viaje el cielo (1777), dedicado a Carlos III "con motivo del feliz parto de la Princesa Nuestra Señora":

Tengo cuidadosamente observado que solamente se disgustan del verso pentámetro, o sea verso de Berceo, los que no saben leer; aquellos que leen como conviene, o le han oído leer de este modo, le juzgan armonioso, magestuoso y digno. Por estas calidades le he escogido para un asunto tan sublime,

o sea el parto de la princesa. (Claro que a todos los ilustrados les importaba contar con el favor del monarca.)

Trigueros, que en "El Hombre" arremete contra los nobles, casta frívola e inútil - "Sus celebrados padres, que tan útiles fueron, / derecho de no serlo por herencia les dieron..."-, zahiere del mismo modo, en San Felipe Neri al clero, a la negra masa de curas y frailes:

Sed útiles a todos: en la humana jornada ¿qué sirve a Dios, ni al mundo, quien no sirve de nada?

¿Seréis acaso dignos de ser más venerados porque, en ocio indolente y oscuro sepultados,

a la sociedad toda sirváis de inútil peso?...

Naturalmente los ilustrados, y en especial los del círculo de Olavide - los "rojillos" de entonces-, aplaudieron a Trigue$\operatorname{ros}^{24}$. En cambio, el muy reaccionario Juan Pablo Forner lo atacó ferozmente. Al final de las Exequias de la lengua castellana se lleva a cabo un gran auto de fe con varios "detestables abortos

24 Aguilar Piñal, p. 151, cita a cierto Raulin d'Essars, que dice en una carta de 1783 (¿dirigida a Olavide?): “Quant à vos poètes, je n'en voudrois que ceux qui ressemblent au Poète Philosophe pour la clarté et la pureté... Nous n'avons plus de Corneilles... [etc.], pas un poète à comparer à votre Filósofo. Les anglois même doivent dans son genre le mettre au dessus de leur Pope" (!). - Un admirador constante de Trigueros fue Juan Nepomuceno González de León, editor de las Poesías filosóficas, que en el prólogo de "El Hombre" le sugería a Sedano, cuyo Parnaso estaba en curso de publicación, incluir en él a este astro naciente, que es "un joven castellano, educado en Sevilla". (Trigueros, nacido en Orgaz, provincia de Toledo, tenía 38 años en 1774.) -Sedano decidió, sensatamente, excluir del Parnaso a los poetas vivos. Los únicos del siglo XviII que hay en él, Luzán y "Jorge Pitillas", eran ya difuntos. 
de la barbarie". Uno de los ganapanes que actúan de verdugos arroja a la hoguera, "descuartizándolo antes",

un rollizo tomo de versos alejandrinos en frigidísimo y barbarísimo romance, cuyo autor tuvo la moderación de apellidarse poeta filósofo...

La rancia novedad de la poesía alejandrina mereció solemnísimos silbos de la mosquetería del Parnaso, viendo que los cuatro martillazos que a unas mismas distancias, en cada dos versos, descarga la tal poesía sobre la pobre oreja española, destruían en ella la varia y fecunda armonía de nuestra lengua..., y desde luego convinieron en que un poeta filósofo que desempeñaba su título echando por tierra la gala, soltura y belleza de nuestros números, debía tener una filosofía orejuda y una poesía muy machacona... [etc.].

El repudio estético es en el fondo, como suele suceder, un repudio ideológico. Menéndez Pelayo, tan reaccionario en sus tiempos como Forner en los suyos, mete naturalmente a Trigueros en el infierno de los Heterodoxos; y, naturalmente también, arremete contra sus pentámetros: "No puede darse cosa más abominable y prosaica: los llamados pentámetros son alejandrinos pareados a la francesa. ;Gran progreso hacer retroceder nuestra métrica a la quaderna vía de Gonzalo de Berceo y al martilleo acompasado del mester de clerecía!"25

Más que el "martilleo" (que por lo menos le hace pensar en Berceo, esa bonita antigualla), lo que molesta a don Marcelino es la disposición en dísticos. Dice a continuación: "Por entonces nadie siguió a Trigueros; pero como no hay extravagancia que no tenga eco, las parejas de alejandrinos han resucitado en nuestros días por torpe imitación francesa, sobre todo en Portugal, donde Antonio Feliciano de Castilho y su hijo y sus amigos lo han vuelto a poner de moda".

Este párrafo merece comentario. Lo que inmediatamente salta a la vista es el desorbitado parti pris de don Marcelino. ¿Qué odio para todo lo que huela a francés!26. Es la misma

${ }^{25}$ Historia de los heterodoxos españoles, ed. de 1947, t. 5, p. 410. Pero don Marcelino se interesó en el "invento" de Trigueros, pues mandó copiar para su biblioteca el tratado De la rima de don Cándido María, manuscrito de la Colombina de Sevilla: cf. BBMP, 39 (1963), p. 373.

26 Véase también lo que dice en su Bibliografía hisp.-lat. clás., ed. cit., t. 9, p. 233: la traducción de las Geórgicas de Virgilio por A. F. de Castilho (1867) 
inquina que mostrará frente a los modernistas, esos "pájaros tropicales" afrancesados que a veces se descuelgan por Madrid $^{27}$. Si en 1880 (fecha de los Heterodoxos) uno de esos pájaros hubiera escrito e impreso ya el Coloquio de los Centauros, Menéndez Pelayo lo habría puesto irremisiblemente en la picota. En 1880 puede decir todavía, con un suspiro de alivio, que en España nadie, fuera de Trigueros, hizo parejas de alejandrinos: el contagio - porque era como si los dystiques fueran portadores de gérmenes volterianos y libertarios- sólo había llegado a Portugal 28 .

Lo más notable es la afirmación de que "por entonces nadie siguió a Trigueros", nadie hizo pareados de alejandrinos. Lo que ocurrió fue justamente lo contrario. En verdad, don Marcelino quiere engañarse a sí mismo; no podía ignorar que Iriarte, amigo de Trigueros, incurrió por ese "entonces" (1782) en los aborrecibles dísticos (fábulas VII y X):

En cierta catedral una campana había que sólo se tocaba algún solemne día...

Yo leí, no sé dónde, que en la lengua herbolaria, saludando al tomillo la hierba parietaria...

En 1892 dedicará Menéndez Pelayo cierta atención a otro seguidor de Trigueros, el patriota chileno Camilo Henríquez (1763-1825), autor de un poema en "pentámetros" que comienza:

es "la mejor que hay en portugués"; por desgracia "tuvo Castilho el mal gusto de hacer su traducción en alejandrinos pareados, intolerable para todo ó do peninsular. Tal fue la manía de sus últimos años, y lo peor es que ha tenido imitadores y discípulos". -Del fragmento de las Geórgicas traducido por el peruano Paz-Soldán (también 1867) no dice nada don Marcelino (ibid., p. 224), quizá porque no está en pareados. -Sobre los pareados de Trigueros véase también esa Bibliografía, t. 8, pp. 218-219 y 379-380.

${ }^{27}$ Carta a Juan Estelrich que cito en mi edición de la Juana de Asbaje de Amado Nervo, México, 1994, pp. 188-189, nota.

${ }^{28}$ Con idéntico suspiro de alivio dirá (en sus Orígenes de la novela) que la Lozana andaluza, "libro inmundo y feo", fue gracias a Dios "una producción aislada": no dejó huella alguna "en nuestra literatura". Cf. B. W. WARDROPPER, "La novela como retrato", NRFH, 7 (1953), p. 475, con las notas. -En mis "Avatares barrocos del romance", NRFH, 26 (1977), p. 412, nota, comento el desdén de Menéndez Pelayo por cierto "nuevo metro" que usó sor Juana, y la pulla que a este propósito les lanza a los "vates modernistas". 
Los talentos de Chile yo te vi que aplaudías, pero su sueño y ocio sempiterno sentías... ${ }^{29}$.

Viéndolo bien, desde Trigueros hasta hoy no ha habido solución de continuidad en la historia del alejandrino: después de Iriarte vendrá Alberto Lista, y luego vendrán Zorrilla y los demás.

Por otra parte, Trigueros propició el redescubrimiento de las joyas poéticas de la Edad Media, no conocidas en ese "entonces" sino por dos o tres anticuarios. Fue necesario que uno de ellos, Pérez Bayer, le revelara al público que los alejandrinos "ya existían". Y otro anticuario, Tomás Antonio Sánchez, se apresuró a imprimir la primera edición de algunas de esas joyas: en 1779, apenas cinco años después de las primeras Poesías filosóficas, apareció en efecto su Colección de poesías anteriores al siglo XV, donde están Berceo y el Arcipreste (y también el Poema del $\mathrm{Cid})^{30}$. En verdad, si acaso Trigueros es culpable de haberse ostentado como inventor del "pentámetro", bien podemos exclamar: O felix culpa!

La fábula X de Iriarte está hecha en "alejandrinos de 14 sílabas", los tradicionales, mientras que la VII, de "pareados de 12 y 13 sílabas a la francesa", está hecha muy adrede de otra manera: alternan rigurosamente las rimas femeninas y las masculinas en los dísticos, y así el verso "En cierta catedral una campana había" tiene 13 sílabas, y el verso "cuatro golpes o tres solía dar no más" tiene 12. Para el oído moderno, tan alejandrinos son los versos de una fábula como los de la otra. Lo que sucede es

${ }^{29}$ Historia de la poesía hispano-americana, ed. de 1958, t. 2, pp. 270-275. (No estará de más subrayar el hecho de que los alejandrinos de Henríquez son los primeros que se hicieron en suelo americano.) Naturalmente, don Marcelino detesta a ese fraile apóstata, uno de los primeros independentistas, hereje hecho y derecho, y -consecuencia lógica- "detestable poeta". Al menos, dice, Trigueros versificaba correctamente, pero Henríquez ni eso.

30 "[Existiendo] tantas poesías antiguas de verso alejandrino -se burla Sánchez-, no dejará de haber caído en gracia a los eruditos la invención de la nueva aldeílla" (citado por Marasso, p. 141). Pero, aparte de deber a Trigueros el estímulo para dar a luz la Colección, Sánchez mismo visitó la aldeílla componiendo en alejandrinos un "Loor al maestro Gonzalvo de Berceo", dizque "procedente de un manuscrito antiguo" (NAVARro, § 254); y también se hizo "secuaz" de Trigueros al aceptar la identificación (bastante irreal) que éste hizo del alejandrino con el pentámetro latino (ed. de Berceo, pp. xii-xiv; ed. del Arcipreste, p. x). 
que la alternancia de rimas femeninas y masculinas, tan propia del alexandrin clásico, no pudo aclimatarse en español.

Alberto Lista, que viene en seguida ${ }^{31}$, introdujo una innovación de mucha trascendencia. Antes de él, la acentuación había sido libre: los acentos caían en cualquier lugar del verso ${ }^{32}$. Henríquez Ureña, que al comienzo de su artículo pasa revista a una docena y media de poetas, de la época medieval a la moderna, en ningún caso encuentra antecedentes de uniformidad acentual en alejandrinos como estos de Lista ("El deseo", $B A E$, t. 67, p. 362):

Ya de fulgentes flores se adorna primavera; el céfiro apacible discurre por el prado; verdura deleitosa el plácido collado y el mirto florecido corona la ribera...,

donde todos los hemistiquios tienen como base un ritmo yámbico constante: tarán tarán taránta ${ }^{33}$. Esta regularidad nos molesta a los lectores de hoy, pero fue la que, gracias sobre todo a Zorrilla, imperó durante largos decenios. El lugar de Lista en la historia del alejandrino es muy relevante.

(Además, Lista prestó oído al octosyllabe francés, o sea el eneasílabo, metro muy poco practicado en la poesía española ${ }^{34}$. Así como Góngora combinó alejandrinos, endecasílabos y heptasílabos, así él combinó endecasílabos y eneasílabos en un poema traducido del francés "con iguales metros":

31 No cuento a Leandro F. de Moratín, amigo también de Trigueros, que dedicó a cierta dama francesa un breve epigrama: "La bella que prendió con gracioso reír / mi tierno corazón, alterando su paz...”.

32 NAVARro, § 394, apoyado en CARlos BARRERA, "El alejandrino español", $B H i, 20$ (1918), 1-26, dice que "las combinaciones formales del alejandrino", de acuerdo con su acentuación, "suman 144 variedades" (!).

33 Lista fue miembro prominente de la Academia de Letras Humanas de Sevilla (Arjona, Matute, Blanco White, Reynoso, etc.), cuyas actividades quedaron registradas en un voluminoso manuscrito conservado en la H.S.A. (MoÑino y BREY, Catálogo, núm. XCIII). Hay aquí una traducción anónima de la héroïde de Blin de Sainmore "Sapho à Phaon" ("Quoi! tu ne reviens point! et par un long silence...”) hecha en alejandrinos (“¿Que tú no volverás? ¿y un silencio espantoso...?”). MARASso observa, atinadamente (pp. 86 y 123), que ni Espronceda (lector de Lamartine y de Hugo) ni Bello (traductor de "La oración por todos") se atrevieron a versificar en alejandrinos.

34 Iriarte había hecho, se diría que a título experimental, un "romance en versos de 9 sílabas" (fábula XIV: "Si querer entender de todo / es ridícula presunción...”). Y cf. supra, nota 11, e infra, nota 40. 
Verde enramada, tu frondoso abrigo oculte al prado mi dolor:

sé de mi llanto eterno y fiel testigo, pues que lo fuiste de mi amor...)

A propósito de los alejandrinos "inventados" por Trigueros dice Menéndez Pelayo: "La gloria (si hay gloria en esto) de haberlos devuelto al tesoro de nuestra métrica, pertenece enteramente a la escuela romántica y de un modo especial a Zorrilla, que tanto usó y abusó de ellos, y cuyas famosas Nubes sirvieron a nuestros versificadores de principal dechado" 35 . Y Henríquez Ureña observa: "Durante cuarenta años, desde el éxito de Zorrilla, la mayoría de los poetas [españoles y americanos] consideraron obligatoria la forma que él le dio al alejandrino: en comparación con la libertad anterior, hubo de parecer que el rigor acentual creaba una superior estructura rítmica". Yo diría que el prestigio de la estrofa zorrillesca duró no cuarenta, sino más de cincuenta años, pues la plegaria de Zorrilla "A María" ("Aparta de tus ojos la nube perfumada...") es de 1838, y Rubén Darío siguió zorrillizando aun después del Coloquio de los Centauros, que es de hacia 1894. Y me explico fácilmente esa extraordinaria capacidad de seducción. Tendría unos diez años cuando leí por primera vez las Nubes, y quedé fascinado por lo "grandioso" del cuadro, pero sobre todo, evidentemente, por el ritmo armonioso de los acentos y por la alternancia de rimas llanas y agudas:

¿Qué quieren esas nubes que con furor se agrupan del aire transparente por la región azul? ¿Qué quieren, cuando el paso de su vacío ocupan, del cenit suspendiendo su tenebroso tul? [...]

Más grave y majestuosa que el eco del torrente que cruza del desierto la inmensa soledad; más grande y más solemne que, sobre el mar hirviente, el ruido con que rueda la ronca tempestad...

35 Antología de poetas líricos, ed. de 1944, t. 1, p. 368. Merecen subrayarse las palabras si hay gloria en esto, que confirman el aborrecimiento casi patológico de Menéndez Pelayo por el verso alejandrino. Cf. supra, nota 25, su fastidio ante "el martilleo acompasado del mester de clerecía". (Antonio Machado sintió a Berceo de otra manera: "Su verso es dulce y grave: monótonas hileras / de chopos invernales en donde nada brilla...”.) 
Lo mismo debe haberles sucedido a muchos espíritus ingenuos e inocentes. Todavía oigo, o leo, recuerdos de "el ruído con que ruéda la rónca tempestád". Y hay que tener en cuenta otra cosa: en el siglo xix aumentó enormemente el número de lectores de versos. Zorrilla y sus continuadores (Bermúdez de Castro, Selgas, García Tassara, Ruiz Aguilera, Mármol, Abigaíl Lozano, Manuel Machado) supieron darles gusto ${ }^{36}$. Oigamos al argentino José Mármol (“A Rosas, el 25 de mayo de 1843”):

¡Miradlo, sí, miradlo! ¿No veis en el oriente tiñéndose los cielos en oro y arrebol? Alzad, americanos, la coronada frente; ya viene a nuestros cielos el coronado sol...;

oigamos al mexicano José María Roa Bárcena ("Laudanza de los indios"):

Vestigios de otra gente guerrera y poderosa, resto sólo al presente de una tribu gloriosa, que a guisa de relámpagos brillaba y se extinguió, festejan hoy con flores y cánticos y danza a Aquella que dolores convierte en esperanza, y amparo de los míseros y madre se llamó...

"Esta estrofa de grandes alas, que quizá nos parezca ahora excesiva" - dice MARASSO, pp. 120-121- fue invento de García Tassara en su poema "Dios".

No pocos premodernistas y aun modernistas siguieron practicando el alejandrino zorrillesco, en estrofas de cuatro, cinco, seis versos y aun más. Así Gutiérrez Nájera, Julián del Casal y Salvador Rueda (además de Darío), recordados por NAvaRRO, § 395, el cual observa, y no sin razón, que el abandono del alejandrino de acentuación regular "puede servir de indicio

${ }^{36} \mathrm{El}$ éxito de las estrofas alejandrinas de Zorrilla se parece al de los versos de arte mayor de Juan de Mena en los siglos xv y xvi. Es claro que los lectores no percibían su regularidad acentual como "martilleo", sino como ritmo. El desconcierto de los primeros lectores de Boscán y Garcilaso se parece al de muchos lectores del Coloquio de los Centauros. Todavía en 1923, José María Aguado ("Tratado de las diversas clases de versos castellanos", BRAE, 10, pp. 445-446) se escandaliza por las libertades que se permitió Darío, y deplora que los poetas españoles lo sigan "en el desvarío de su pretensión”. 
para calcular la fecha de algunas poesías" (por ejemplo de Guillermo Valencia). Quien se mantuvo siempre fiel a la modalidad zorrillesca fue Antonio Machado.

Otra regularización romántica es la anapéstica, introducida por Rosalía de Castro (hemistiquios de dos acentos: tararán tararánta, y no de tres: tarán tarán taránta):

Ya no mana la fuente, se agotó el manantial, ya el viajero allí nunca va su sed a apagar...

"El alejandrino francés -observa Henríquez Ureña-, el de Corneille y Racine, tendía de preferencia a este ritmo anapéstico, con cuatro acentos" ("Mais tout dort, et l'armée et les vents de Neptune"). Varios modernistas cultivarán la modalidad anapéstica: José Joaquín Pérez, Rueda, Nervo, Chocano. Es la acentuación, muy estricta, de uno de los poemas más representativos del modernismo: la "Sonatina" (1895) de Rubén Darío37.

Aunque ligeramente posterior al Coloquio de los Centauros, la "Sonatina" parece ser el adiós de Rubén al alejandrino de acentuación regular ${ }^{38}$. El Coloquio viene a ser una especie de Marsellesa. La "revolución modernista" consistió, primero que nada, en devolverle al alejandrino la libertad acentual de que había venido gozando hasta que llegaron Lista y Zorrilla ${ }^{39}$. Y esta libertad trajo consigo otras, por ejemplo la de "modificar la correspondencia que ordinariamente se había observado entre el orden sintáctico del verso y la división métrica de los hemisti-

37 El cual, como dice NAvARro, § 396, "parece que no volvió a emplear esta clase de alejandrino como forma independiente en ninguna otra ocasión". -Hay también la regularidad dactílica inventada por la Avellaneda ("Soledad del alma"): "Sale la aurora risueña, de flores vestida, / dándole al campo y al cielo variado color..."; pero estos versos -y algunos de Ruiz Aguilera-, aunque de 14 sílabas, no pueden llamarse alejandrinos. Una sola vez hizo doña Gertrudis alejandrinos zorrillescos ("Al mar"): "Suspende, mar, suspende tu eterno movimiento, / por un instante acalla el hórrido bramar...".

38 Todavía en 1908 hará estrofas zorrillescas $A B A B$ con $B$ agudo: "Luxembourg otoñal de un día melancólico; / los árboles dorados envuelve la hoja gris...". Cf. también "A doña Blanca de Zelaya” y "Retorno". Pero son excepciones.

39 NAvarro, $\S 328$ y 395 , da varios ejemplos de románticos que, como Esteban Echeverría, nunca se ciñeron a un molde rígido, y de modernistas que, como Nervo, dejaron de zorrillificar a partir de cierto momento. 
quios" (NAVARRo, § 394). En este sentido, los modernistas hicieron algo que sólo Sem Tob había hecho (cf. supra, p. 364).

También son "modernos", o mejor, extrañamente "premodernistas", los alejandrinos de don Sinibaldo de Mas, teórico de la versificación y versificador ad hoc. En su Sistema musical de la lengua castellana, publicado por primera vez en Barcelona en 1832, trata "De los metros fundados en el acento prosódico", desde los de 7 sílabas hasta los de 16 (4ª ed., París, 1874, pp. 63 ss.). Don Sinibaldo parte de cero; no cita versos españoles ni siquiera a propósito de los de 8 y de 11 sílabas $^{40}$.

Él no emplea la palabra alejandrino, y siente -como Iriarte, a quien tampoco cita- radicalmente distintos los versos de 13 y los de 14 sílabas. Los dos ejemplos que pone no dejan lugar a dudas. En los de 14 los hemistiquios terminan sistemáticamente en palabra llana, y no hay posibilidad de hacer sinalefa entre una mitad del verso y la otra:

Ni los árboles verdes cubiertos de azahares ni las límpidas perlas que inundan las praderas...

El verso de 13 - "tredecasílabo" - es otra cosa, y a él dedica el autor del Sistema más atención que a ningún otro. Hay más doctrina y sobre todo más ejemplos. Uno de ellos es un soneto (p. 72), "Fragante y rubicunda entre sus hojas bellas / es la rosa al nacer, de célica figura...", - que seguramente es el primero que se hizo en lengua española desde el de Pedro Espinosa. Me detendré en otro de los ejemplos ("El campo", pp. 72-73), hecho en versos sueltos:

Codicien otros la ciudad, que su bullicio ya por siempre abandono con ligera planta y nunca en ella a verme volverán los hombres. Del aire juguetón la plácida frescura, la vista deliciosa de estos campos bellos...

40 Para el de 11, ejemplificado sumariamente con un verso aislado, "Mil flores olorosas la mañana", tiene este comentario: "Éste es el endecasílabo que han usado todos nuestros poetas. Pasemos a otro" (o sea al de 12 sílabas). Los ejemplos que va poniendo son siempre de su propia minerva. (Es curiosamente heroico el ejemplo de versos de 9: “iAl arma, hijos del Cid, al arma! / Se empuñe el formidable fierro...") 
Los versos tienen materialmente 13 sílabas ${ }^{41}$, pero son alejandrinos sometidos a licencias más o menos serias, las cuales obliteran la cesura, o al menos la emborronan. Nada más fácil que leerlos como los que varios decenios después harán los modernistas:

Codicien otros là | ciudad, que su bullicio ya por siempre abandó|no con ligera planta y nunca en ella a vér|me volverán los hombres.

Del aire juguetón | la plácida frescura, la vista delició|sa de estos campos bellos... ${ }^{42}$

Son versos como los de Iriarte en la fábula VII: un hemistiquio de 6 sílabas y otro de 7 . En Iriarte la cesura está siempre a la vista: el final del primer hemistiquio es, o palabra aguda ("En cierta catedral"), o palabra llana que hace sinalefa con la vocal inicial del segundo hemistiquio (leyendo "que sólo se tocaba algún solemne día", y no "que sólo se tocaba | algún solemne día” ${ }^{43}$. Esto lo hace también don Sinibaldo: "del aire juguetón | la plácida frescura"; "fragante y rubicunda | entre sus hojas bellas". Pero su truco predilecto es cortar en dos la palabra central. En "ya por siempre abandono con ligera planta", el primer hemistiquio viene a ser "ya por siempre abandó-", y el segundo "-no con ligera planta"44. Uno de sus ejemplos (p. 66, traducción de un pasaje de los Tristia de Ovidio) está hecho exclusivamente con esta clase de versos: "Las modestas vió|las que rapazuelos tiernos / y doncellas festí|vas van cojiendo sueltas..."45. En un pasaje de "La pastora" (p. 67) se lee que ni ár-

${ }^{41}$ Obsérvese cómo, según esta doctrina, "En el nombre del Padre que fizo toda cosa" es verso de 14, pero "Quiero fer una prosa en román paladino" es de 13.

42 Marco con una raya vertical las cesuras, obliteradas o no; y para mayor claridad añado acentos.

43 Iriarte no los llama versos de 13 sílabas, sino "de 12 y 13 ”, porque los de rima masculina tienen todavía una sílaba menos que los de rima femenina: el verso "con el más recio son, con pausado compás" está hecho materialmente de doce sílabas.

${ }^{44}$ Son como las "cisuras" que a veces se hicieron en el siglo xvI: "y mientras miserable- / -mente se están los otros abrasando" (fray Luis de León), "perma- / -neciendo siempre en tantas desventuras" (Aldana). Cf. mi "Francisco de la Torre...”, NRFH, 47 (1999), nota 61.

45 Doce versos reproducidos por Menéndez Pelayo en Bibl. hisp.-lat. clás., t. 7 , p. 280. 
boles, ni perlas ni flores "aliviar de mi pecho han | podido las dolencias", con un final de hemistiquio, échoan, que se adelanta a osadías de Juan Ramón Jiménez como las que luego veremos.

Son, para usar la designación de Henríquez Ureña, "alejandrinos descoyuntados", bastante frecuentes en la poesía modernista ${ }^{46}$. Los descoyuntadores más asiduos fueron Rubén Darío (a partir del Coloquio de los Centauros) y Juan Ramón Jiménez. Elijo al azar unas muestras del uno y del otro. En las parejas que hago, el primer verso es de Darío y el segundo de Juan Ramón. (Pongo acento grave en las vocales que en el habla normal son átonas.)

1. Los que auscultasteis èl | corazón de la noche... rayan, constantes, èl | falso cielo de lluvia...

2. en tanto suena là | música pitagórica... que colgabas a là $\mid$ tarde de primavera...

3. yo, silencioso en ùn | rincón tenía miedo... de vez en cuando, en ùn | jesto rápido y único...

4. no sé si a veces sù | verbo ágil al conceto... inspirándose en sù | vejez de tomo y lomo...

5. acaso piensas èn | la blanca teoría... gotea mundos èn | la sombra de tu frente...

6. es recordado pòr $\mid$ mis íntimos sentidos... corría el agua pòr | el lado del camino...

7. al son del arpa què | melodiza el Guignol... surgen lo mismo què | pedazos de luceros...

8. con las alondras ỳ | con Garcilaso y con... sublime de altas $y \mid$ trasfiguradas torres...

9. ¡Oh Sor María! ¡Oh Sòr | María! ¡Oh Sor María!... de las ruïnas, dè | las fuentes, de las flores... ${ }^{47}$

46 Véase E. DíEz EchARRI, "Métrica modernista: innovaciones y renovaciones", RLit, 11 (1957), en especial pp. 111-113.

47 Sor Juana es muy aficionada al juego -imitado de Calderón- de terminar octosílabos agudos con voces átonas, por ejemplo en el "Prólogo al lector": "no hay cosa más libre què / el entendimiento humano"; “...el corto espacio / que ferian al ocio làs / precisiones de mi estado"; "pues al cabo harás lo què / se te pusiere en los cascos; / y adiós, que esto no es más dè / darte la muestra del paño". 
Todo esto podría proceder de la doctrina de Sinibaldo de Mas ("codicien otros là | ciudad, que su bullicio..."), como también los descoyuntamientos "totales" ("la vista delició|sa de estos campos bellos...", "embelesa los bós|ques de verdor cubiertos..."). Éstos son frecuentísimos en Darío:

y el duelo de mi cò|razón, triste de fiestas...

lleva la lengua mù|sical el vago viento...

maravilloso chàm|piñón decorativo...

ha nacido el apò|calíptico Anticristo...

y en tanto que el Medi|terráneo me acaricia...

dejad la responsà|bilidad a las normas...

y los moluscos rèmi|niscencias de mujeres...,

y lo mismo en Juan Ramón:

por las marmóreas gà|lerías se entra el puerto...

bajo el cenit se tràs|parenta el caduceo...

entre la risa fà|miliar, en la terraza...

el mirador, el càm|panario, la melena...

leves suspiros, î|risadas mariposas...

enarcados, elè|gantemente, los galgos...

que encenderán para ó|tros ojos, otros dedos...

Pero Juan Ramón llega más lejos que su maestro: en los versos

te derramas, llorando en | las estrellas virjinales...

las golondrinas van en | las ondas indolentes...

huyen las nubes èn la | fugitiva corriente...

se han encendido frènte al $\mid$ crepúsculo amatiste...,

los primeros hemistiquios terminan, respectivamente, en bisílabos llanos: -ándoen, -ánen, -énla y -énteal.

Claro que ni Rubén ni Juan Ramón hicieron -como Iriarte o como Sinibaldo de Mas- poemas enteros en alejandrinos "de 13 sílabas". La eficacia de los alejandrinos descoyuntados consiste en su intercalación, sorpresiva, entre los "normales". El lector que trae en la cabeza el ritmo de los alejandrinos lo sigue reconociendo y sintiendo en el alejandrino "anormal" que de pronto le sale al paso. Y no hay necesidad de mucha teoría para ver cómo la "ruptura del sistema" tiene, en casos como éste, un efecto estético. Alejandrinos como "enarcados, elè|gantemente, los galgos", o como "y los moluscos rèmi|niscencias de muje- 
res" son sin duda atrevidos, pero los poetas saben hasta dónde llevar el atrevimiento. Al final de su "Epístola a la señora Lugones", después de preguntar "Mas ¿dónde está aquel templo...?”, prosigue así Darío:

¿Dónde los hombres ágiles que las piedras redondas recogían para los cueros de sus ondas?

Extraño hemistiquio de seis sílabas: "recogían para". Hay que sentir, por fuerza, uno como acento en la segunda sílaba de "para": parà. Y he aquí el primer terceto del soneto "Yo persigo una forma":

Y no hallo sino la palabra que huye, la iniciación melódica que de la flauta fluye y la barca del sueño que en el espacio boga.

Leído tal cual, el primero de estos versos no tiene sino 11 sílabas en vez de 14, y parece cojo en relación con los otros dos, de ritmo tan claro. Pero basta acentuar sinó y hacer hiato entre no y hallo (y entre que y huye) para que sea perfectamente satisfactorio ${ }^{48}$. Los hiatos son mucho más frecuentes en Juan Ramón. Considérense estos tres versos:

mas es más claro el $\mid$ ondear de las mieses... el mundo se abre y $\mid$ los techos de pizarra... qué fervor pone en $\mid$ el precioso estribillo...

Aparte de que hay que leer con una especie de acento los monosílabos átonos $\mathrm{el}, \mathrm{y}, \mathrm{en}$, hay que hacerlos preceder de un hiato. "Banquera" (Segunda antolojía poética, 1922, núm. 144) es un caso especial: la proporción de alejandrinos "anormales" es muy grande; Juan Ramón tiene que haberlos hecho así adrede, para adecuarlos a la burla y caricatura de la "banquera" del título, que es una prestamista vieja y aborrecible. Y aquí, cosa curiosa, pone Juan Ramón, al final, esta notita: "Alejandrinos de cobre".

48 Alfonso Méndez Plancarte, siempre alerta a los fenómenos métricos, dice de ese verso de Darío: "No es muy verosímil que sea un endecasílabo único entre esos alejandrinos" (ed. de sor Juana, t. 3, p. 546). Yo digo que no es nada verosímil. (Sería, además, un endecasílabo muy torpe). -También son atrevidos, aunque no tanto, versos como "ojos de víboràs | de luces fascinantes" y "para ofrecérselòs | al dios sagrado y fiel". 
En conjunto, el manejo del alejandrino es igual en el maestro y en el discípulo. Pero ¿quién persuadió a Darío a abandonar las regularidades zorrillescas, tan exitosas? Marasso da a entender que Darío leyó a Sinibaldo de Mas (después de 1882), lo cual es verosímil, tanto más cuanto que la última edición del Sistema musical de la lengua castellana es de París, 187449; pero no hay señas de que esa lectura, si la hubo, haya dejado huella en él. En cambio, es seguro el papel del salvadoreño Francisco Gavidia (1863-1946), que en 1881 se puso a analizar - muy de veras, y no sin trabajos- los alejandrinos franceses y en 1883 tradujo en alejandrinos ya no zorrillescos la "Stella" de Victor Hugo. Estos alejandrinos rompen, en efecto, la correspondencia entre la estructura sintáctica y el metro. Un verso gavidiano como "Desperté. Vi la estrella de la mañana. Ardía..." debe de haber sonado violento y feo en oídos acostumbrados a las cadencias imperantes. Además, en este caso tenemos el testimonio clarísimo de Darío (Autobiografía): "Fue con Gavidia, la primera vez que estuve en aquella tierra salvadoreña, con quien penetré en iniciación ferviente en la armoniosa floresta de Víctor Hugo; y de la lectura mutua de los alejandrinos de [Hugo] que Gavidia el primero, seguramente, ensayara en castellano a la manera francesa, surgió en mí la idea de renovación métrica que debía ampliar y realizar más tarde". La primera vez que estuvo Darío en El Salvador fue en 1882. Gavidia tenía 19 años y él 15 . El reconocimiento del más joven es muy natural ${ }^{50}$, pero también es claro que lo que más cuenta es lo que Darío iba a "ampliar y realizar más tarde". Lo cual hizo, como es obvio, gracias a su lectura personal de $\mathrm{Hu}-$ go, Leconte de l'Isle, Verlaine y tantos otros. Ellos, y no don Sinibaldo ni Gavidia, fueron sus verdaderos maestros ${ }^{51}$.

Rubén Darío aprendió despacio. En 1885 escribió su largo poema "Víctor Hugo y la tumba" en alejandrinos, pero plenamente zorrillescos: estrofas $A A B-C C B$, con los versos $B$ agudos. $\mathrm{Al}$ traducir en 1886 "La entrada en Jerusalén" del mismo Hugo, comenzó con seis estrofas de esa misma hechura, pero luego,

49 Quien ciertamente leyó el Sistema musical es Manuel González Prada, pues lo cita en las notas de sus Exóticas, 1911 (cf. NAvarro, § 394).

${ }^{50}$ El homenaje de Darío "A Francisco Antonio Gavidia”, escrito en 1894, es un largo poema en endecasílabos sueltos (con uno que otro heptasílabo).

51 Juan Felipe Toruño, Gavidia, San Salvador, 1969, pp. 41-59, tiende a exagerar la importancia del salvadoreño. 
se diría que fatigado por el esfuerzo, continuó en metro de silva. Todavía en 1888 creía que el metro más adecuado para traducir a Hugo eran los endecasílabos sueltos o la silva. En silva compuso su poema "A Víctor Hugo" y en silva tradujo fragmentos de "Los cuatro días de Elciis" (de La légende des siècles) ${ }^{52}$. Pero el "Responso" a Verlaine (1896) no está ya en versos italianos de 11 y 7 sílabas, sino en versos franceses de 14 y 9 . Así como Garcilaso - mucho más que Boscán- modernizó la poesía española adoptando el endecasílabo italiano, así Darío la modernizó adoptando el alejandrino francés ${ }^{53}$. A comienzos del siglo XVI, italianización; a fines del XIX, afrancesamiento.

Y así como los poetas españoles se apresuraron a seguir el ejemplo de Garcilaso, así en torno a Darío se formó instantáneamente un círculo de admiradores e imitadores, sobre todo en los países hispanoamericanos. Una manera cómoda de ver lo que fue el modernismo es repasar las páginas de dos notables revistas literarias de México: la Revista Azul (1894-1896) y la Revista Moderna (1898-1903). El elenco de poetas (comenzando con Darío) es casi el mismo en las $\operatorname{dos}^{54}$, y todos ellos, quién más quién menos, parecen compartir la misma sensibilidad y los mismos entusiasmos. Las dos revistas contienen buena cantidad de colaboraciones de diversos países americanos, y tam-

52 Andrés González Blanco, bastante tiempo después, completó la traducción empleando no sólo la silva sino también, en proporción abrumadora, alejandrinos plenamente "modernos". Esta aclaración, que está en la edición del Salmo de la pluma (1924) publicada por A. Ghiraldo y González Blanco, fue suprimida por Ghiraldo en su edición de Obras poéticas completas (1932), "originando - como dice A. Menéndez Plancarte en su ed. de Poesías completas, 1952, p. 1263- confusiones gravísimas para la cronología y la rítmica de R.D.”. En efecto, Navarro (§ 394), que evidentemente no leyó ese caveat, atribuye a Darío unas "audacias" (alejandrinos descoyuntados) que pertenecen totalmente a la parte traducida por González Blanco.

53 Con una diferencia: Garcilaso no hizo sino unas cuantas coplas castellanas, como por juego, mientras que Darío nunca abandonó los metros tradicionales. -Juan Francisco Sánchez, De la métrica de Rubén Dario, Ciudad Trujillo, 1955, tuvo la paciencia de contar el número de versos de toda clase de metros que escribió Darío. Los más frecuentes son el octosílabo (30\%) y el endecasílabo (26\%), y les sigue el alejandrino (13\%).

${ }^{54}$ En 1988 y 1987, respectivamente, la UNAM publicó excelentes facsímiles de las dos. Los volúmenes de la Azulson: 1 (1894); 2 (1894-95); 3 (1895), 4 (1895-96) y 5 (1896). Los de la Moderna son seis, uno para cada uno de los años que van de 1898 a 1903. Como cada volumen tiene su índice de colaboradores, me limitaré a dar el nombre del poeta y el volumen de la Revista Azul (abreviaré $A$ ) o de la Revista Moderna (abreviaré $M$ ) en que aparezca. 
bién algunas de España. Los poetas se dedican poemas unos a otros. En $M-2$, por ejemplo, Jesús E. Valenzuela, director de la Moderna, dedica un poema "A Leopoldo Lugones, en París" 55.

No pocos de los modernistas - comenzando naturalmente con Darío- se muestran tan deslumbrados por el alejandrino como por los temas y ambientes "paganos" a la francesa. Puede servir de ejemplo un poema de Rubén M. Campos, "Sátiros y Ninfas" (M-2), que comienza:

La Cólquida. Un oasis de plátanos dorados.

Un pequeñito prado abierto. Entrelazados,

los bejucos hamacas fingen de rubia seda.

Abajo, en un declive, murmurio de agua leda...,

y que termina:

...en el paisaje eglógico de plátanos dorados

solamente se escuchan los sones encantados

de la syringa: el Sátiro soñador, a su anhelo

carnal, prefirió su arte que lo encumbra al cielo.

Otros poemas en pareados de Rubén M. Campos, futuro musicólogo y folklorista, son "Combate de Centauros y Lapitas" en $M-1$ ("De Piritóo en las bodas truena el tropel equino / de los Centauros...") y "Ninfas y Centauros" en $M-2$.

$\mathrm{Ni}$ el Coloquio de los Centauros ni los poemas en dísticos que hay en estas revistas ${ }^{56}$ imitan el modelo francés hasta el grado

55 En París, pero no en una embajada, ni en un ministerio, ni en una redacción de periódico, sino en el café Cyrano, a un paso de "las aspas de pecado del Moulin Rouge", se conocieron Darío y Nervo, el cual cuenta (M-3) de qué hablaron: "de la nueva literatura en América; de nuestro Gutiérrez Nájera, de Julián del Casal, de Lugones, de Tablada, de Jaimes Freyre, de la muerta Revista Azul, precioso zafiro de arte que fue, y de la Revista Moderna en que con Valenzuela ofician buenos diáconos. De todos, con amor".

${ }^{56}$ Hay alejandrinos pareados en A-2 (Balbino Dávalos, poema reproducido en $M-2)$; en $M-1$ (Tablada, Campos); en $M-2$ (Campos, Valenzuela); en M-3 (Tablada, Campos, A. Lezcano, F. M. de Olaguíbel); en M-4 (Tablada, J. A. Silva); en M-5 (A. Carías, Valenzuela, Nervo, J. A. Silva, Tablada [traducción del largo poema dramático El rey Galaor de Eugénio de Castro]), y en $M-6$ (Nervo). - El nombre de José Asunción Silva, en $M-4$, va seguido de un "epíteto", en cursiva: el Precursor. Pero ya otro de los precursores del modernismo, Manuel José Othón, había hecho pareados de alejandrinos en 1879: cf. infra, p. 397. 
de alternar rimas femeninas y masculinas. Por otra parte, más que en pareados, los alejandrinos se presentan en poemas estróficos y en sonetos. Muchos de los estróficos siguen teniendo molde zorrillesco: las combinaciones más frecuentes son $A B-A B$ y $A A B-C C B$, con los versos $B$ agudos (por ejemplo Rubén Darío en $M-6$ y Guillermo Valencia en $M-2)$; predominan, sin embargo, las estrofas sin agudos (por ejemplo Luis G. Urbina en $A-3$ y $M-5$, José Santos Chocano en $A-5$ y $M-2$, Tablada en $M-2$ y Nervo en $M-4$ y $M-5)$. También hay sonetos de acentuación "zorrillesca" ( $A B A B-A B A B-C C D-E E D$, con los versos $B$ y $D$ agudos), pero son la minoría ${ }^{57}$. Hay también unos pocos poemas que combinan alejandrinos y heptasílabos, sobre todo en estrofas. Otros están en alejandrinos no estróficos, por ejemplo la "Marina" de Rubén Darío que comienza "Como al fletar mi barca con destino a Citeres..." $(M-1)^{58}$.

Me imagino que ya todo está dicho en cuanto a la reacción de los críticos y de los poetas españoles frente a los modernistas americanos. Un hecho es claro: Menéndez Pelayo, el crítico supremo, abominó de ellos y en especial, como se ha visto, de sus afrancesados alejandrinos ${ }^{59}$. En cambio, ni en la Revista Azul ni

57 Quien tiene mayor número de sonetos con agudos es Rubén Darío: $A-4, A-5, M-1, M-2$ (y de hecho, en su producción total, los sonetos con agudos son casi el $50 \%$ ). En cambio, Tablada no tiene sino sonetos de rimas llanas (desde $M-2$ hasta $M-6$ ), salvo uno cuyos 14 versos son agudos ( $M-4$, p. 54), lo cual es otra cosa.

${ }^{58}$ Más tarde hizo retoques, entre los cuales está el acortamiento de tres alejandrinos que obviamente resultaban ripiosos (uno quedó convertido en heptasílabo y dos en eneasílabos). Era una "silva de alejandrinos" y se convirtió en "silva polimétrica". Véase la nota de Menéndez Plancarte, ed. cit., p. 1292.

${ }^{59}$ Desgraciadamente las opiniones vivas, las que se expresan en las tertulias literarias y en charlas de café, no suelen dejar testimonio escrito. Pero es seguro que hubo en Madrid muchas reacciones burlonas. Tengo noticia de dos parodias: de "La princesa está triste..." ("Segismundo está triste, ¿qué tendrá Segismundo?”) (Segismundo Moret era un personajón de fines del siglo XIX) y de "Ya viene el cortejo" (“;Ya viene el pedrisco!”...). Las parodias, sin embargo, son testimonios ambiguos. En el siglo XvI hubo parodias de "Si de mi baja lira..." ("De vuestra torpe lira / ofende tanto el son..."; "Si de tan baja lira / tanto se extiende el son...") y de "iQué descansada vida...!" ("¡Ay Dios, qué triste vida / es donde no se mueve algún ruïdo...!"). Sus autores las habrán hecho pour rire, pero no para rebajar a Garcilaso y a fray Luis. Son testimonio irrefragable de que la poesía parodiada está en boca de todos. -MAx HenríQuez Ureña, Breve historia del modernismo, 
en la Moderna hubo posturas combativas contra la antigua metrópoli (han quedado atrás los tiempos de "¡Nos hemos sacudido el fiero yugo hispano!”). Lo que sí hubo, una vez, fue una defensa del modernismo: en respuesta a cierto artículo de Ramiro de Maeztu en El Imparcial de Madrid, Manuel Ugarte publicó en $M-6$, pp. 142-143, una réplica mesurada e inteligente, "El francesismo de los hispanoamericanos". Por lo demás, en una y otra revista ocupan buen lugar los españoles: Ruiz Aguilera, Núñez de Arce, Federico Balart, Marquina, y sobre todo Campoamor y Manuel Machado ${ }^{60}$.

Las dos revistas fueron cosmopolitas. En ellas figuran D'Annunzio, Edmondo d'Amicis, Heine, Tolstoi, Lord Byron, Swinburne, Wilde, Whitman y Poe. La Moderna se dio el lujo de imprimir poesías en su lengua original: "In morte di Giuseppe Verdi" de D’Annunzio ( $M-4)$, "O pagem" del brasileño Fontoura Xavier ( $M-5)$ y "Proud music of the stars" de Whitman $(M-6)$. Pero quienes predominan, y con mucho, son los franceses ${ }^{61}$. Y las reproducciones en la lengua original son muy numerosas: Théophile Gautier y Leconte de l'Isle, Baudelaire, Mallarmé y Verlaine, Jean Lorrain y Maeterlinck, además de un soneto en alexandrins de Augusto Armas, A-162.

México, 1954, no menciona para nada la hostilidad de Menéndez Pelayo, pero en la p. 512 se refiere a las "burlas y los dicterios" que se hicieron en Madrid hacia 1904-1906, y dice que "el ataque más violento, ya no en broma, sino en tono solemne, fue el de Emilio Ferrari en su discurso de ingreso (1905) en la Real Academia Española”.

${ }^{60}$ Hay también, aquí y allá, fragmentos o cosas breves de Castelar, Echegaray, Ortega Munilla, Unamuno, y hasta de P. A. de Alarcón, Pereda, Valera, Galdós y la Pardo Bazán. -Zorrilla ha quedado atrás: no figura sino una vez (en $A-5)$, y eso por tratarse de "Una poesía inédita". No hay nada de Bécquer, et pour cause. Todo el mundo lo conocía. (Sus Obras, publicadas en Madrid en 1871, fueron pirateadas en México en 1872 por "El Siglo XIX".)

${ }^{61} \mathrm{He}$ aquí, por si a alguien le sirve, una lista casi completa de poetas y prosistas (en orden alfabético): Banville, Baudelaire, Barbey d'Aurevilly, Paul Bourget, François Coppée, Daudet, Dumas fils, Flaubert, Anatole France, Th. Gautier, André Gide (!), los Goncourt, Hugo, Huysmans, Laforgue, Leconte de l'Isle, Lemaître, Jean Lorrain, Pierre Loti, Maeterlinck, Mallarmé, Maupassant, Catulle Mendès, Musset, Prévost, Rachilde, Renan, Samain, Marcel Schwob, Sully Prudhomme, Taine, Verlaine, Zola.

62 El malogrado Augusto de Armas, cubano (1859-1893), pasó sus últimos años en París; se hizo "amigo de los más conocidos parnasianos y simbolistas franceses", y escribió en francés sus Rimes byzantines, Paris, 1891 (cf. M. HenríQuez UreÑa, Breve historia, pp. 421-422). El mexicano Manuel Puga y Acal (1860-1930) no se afilió al modernismo, pero conoció a Verlaine y a 
Uno de los libros-cumbre del modernismo es Las sombras de Hellas, publicado en París, en 1902, por el argentino Leopoldo Díaz, afrancesado hasta la médula de los huesos. Hay una breve invocación "A Palas Athenea", en dísticos, y más de un centenar de sonetos, todos en alejandrinos, con títulos como "La flauta de Pan", "La rueca de Omphale", "Hypnos y Thánatos", "La Ninfa dormida", "La muerte del Efebo", "La tumba de Anacreonte”...; están aquí Diana y Venus Anadiomena, Fedra y Ariadna, Leda y Europa, Helena, Briseida, Casandra, Circe, Nausícaa; hay Centauros y Sátiros, Náyades y Ondinas, hay Nereidas llamadas Glauké y Thaleïa; hay ánforas, pámpanos, copas exquisitas en que se escancia el vino... Y cada soneto lleva a un lado su traducción francesa, por Frédéric Raisin ${ }^{63}$. La reseña de Amado Nervo (en $M-6$, p. 176) es naturalmente muy elogiosa. Pero tiene más interés lo que dice el clarividente Remy de Gourmont en el Préface:

La langue espagnole, qui ne fait plus beaucoup de bruit en Espagne, revit heureusement, libre et rajeunie, dans les vieilles colonies castillanes, devenues de fières républiques... Cette littérature nouvelle ne doit guère à l'Espagne que sa langue; ses idées sont européennes. Sa capitale intellectuelle est Paris... L'auteur du livre que voici est un de ceux qu'un long séjour parmi nous a familiarisés avec nos habits intellectuels... On passe sans surprise du texte à la traduction; ce sont d'autres mots, c'est bien la même pensée adroitement rendue jusqu'en ses moindres nuances...; les sonnets français sont les frères jumeaux des sonnets espagnols: Eros et Anteros ${ }^{64}$.

Mal podía prever Remy de Gourmont que muy pronto Juan Ramón Jiménez iba a hacer abundantes poemas en alejandrinos perfectamente modernistas. Juan Ramón tiene que haber leído a Zorrilla y compañía y sucesores, pero no sufrió su influencia; lo que hizo, como se ha visto, fue seguir a Darío en sus licencias y osadías, y llevarlas un poco más allá. En sus libros ju-

Rimbaud, "hizo versos en francés, y al francés tradujo algunas Rimas de Bécquer" (ibid., p. 490). También Darío hizo alexandrins en francés ("Pensée", "Chanson crépusculaire", "France-Amérique").

63 "Il a été tiré de cet ouvrage 20 exemplaires sur papier du Japon"; pero aun los ejemplares del montón, como el mío, son muy bellos: elegantes entêtes y culs-de-lampe, iniciales rojas, buen papel.

64 Cf. supra, nota 24, el espaldarazo de Raulin d'Essars a Trigueros, el poète philosophe. 
veniles, de Primeras poesías (1898) en adelante, el alejandrino está ausente; pero abunda en las Elejías (1907), en La soledad sonora (1908)y en todos los libros que siguieron, y que quedaron antologados en la Segunda antolojía poética (1922). Pero a partir de Bonanza (1911-12) los alejandrinos se hacen raros.

He aquí, para terminar, algunas notas sobre la suerte del alejandrino en la pluma de algunos poetas modernos, elegidos caprichosamente. (Precede al nombre de cada poeta su año de nacimiento.)

1853] Salvador Díaz Mirón (Poesías completas, ed. M. Sol, México, 1997) no tiene en su haber sino dos poemas en alejandrinos (zorrillescos), en estrofas de cuatro y cinco versos (pp. 290 y 515).

1858] Manuel José Othón (Poesía completa, ed. J. A. Peñalosa, San Luis Potosí, 1992) escribió en sus mocedades un par de poemas en alejandrinos: "Nocturno" (1876), estrofas $A B-A A B$ con el infaltable acento agudo en los versos $B$ (pp. 316-318), y "El lago de los muertos" (1879), que tiene primero unas estrofas de a diez versos con acento agudo cada cinco (pp. 337-338) y luego un largo pasaje en pareados (pp. 347-348) nada zorrillescos: no hay en ellos el "martilleo" yámbico ni las rimas agudas y, sobre todo, son pareados. Pero en su edad madura no sólo abandonó Othón por completo el verso alejandrino, sino que en una carta de 1902 los repudió con no poco énfasis ${ }^{65}$.

1866] Balbino Dávalos (Las ofrendas, 3ª ed., Madrid, 1909) es un poeta entre dos aguas. Tiene sonetos clásicos (el de la p. 44, "No os ofendáis, señora, porque os miro...", hasta parece del siglo xvI), pero también, cosa rara, un soneto en eneasílabos

65 Carta publicada por Jesús Zavala en Revista de Literatura Mexicana, 1 (1940), pp. 279-281. Está dirigida a Juan B. Delgado. Comenta cierto artículo reciente de Amado Nervo, que es "una simpleza": "Lo que dice de los metros antiguos y los metros nuevos, es una sandez. ¡Como si hubiera tales! Los puede haber cuando un idioma se está formando, pero no cuando ya está en su madurez y puede decirse que en su decrepitud, como el nuestro. Por otra parte, ese prurito de los llamados modernistas de emplear el alejandrino francés, es una estupidez y un desconocimiento profundo de la índole de ambas lenguas. Estoy seguro que no saben los pobres que el tal alejandrino fue usado en España mucho antes [!] que en Francia. Díganlo si no..." -y aquí Othón pone tres curiosos ejemplos de alejandrinos españoles anteriores a los franceses: el Poema del Cid, los Tres reis d'Orient y la Vida de Santa María Egipciaca. (Por cierto, no dice ni media palabra de sus alejandrinos juveniles.) 
(p. 162) "A M. Stéphane Mallarmé". Un soneto se llama "Pelayo en Covadonga"; en fuerte contraste, otro está dedicado "A pauvre Lélian". Los alejandrinos aparecen en dísticos, o bien en estrofas $A B A B$ (sin agudos) y en sonetos (sólo uno de consonantes llanos y agudos, mientras que en Darío son muchos) ${ }^{66}$.

1871] José Juan Tablada (Poesía, ed. H. Valdés, México, 1971) es gran aficionado al alejandrino, sobre todo en pareados, por ejemplo "El rey Galaor", muy largo (pp. 108-138). Otro poema en pareados, "Interior" (pp. 333-334), está hecho con versos de 16 sílabas $(8+8)$, especie de ampliación del alejandrino, nada rara entre los modernistas ${ }^{67}$.

1871] Enrique González Martínez (Poesía, ed. A. Cámara, México, 1995) cultivó mucho el alejandrino en sonetos, en poemas estróficos -sobre todo de cuatro versos-, en tercetos y en pareados. Pero, al igual que Juan Ramón, acabó por dejarlos a un lado. (Cuento un total de 85 sonetos en alejandrinos, y veo que, en su gran mayoría, pertenecen a los años 1909-1921 y en especial a 1915, el de Jardines de Francia, donde hay traducciones de veinte poetas franceses.) González Martínez hace siempre cesuras ortodoxas, con hemistiquios bien marcados. No es afecto, como Juan Ramón, a los versos "descoyuntados".

1875] Antonio Machado (Obras, ed. J. Bergamín, México, 1940) escribió pocos alejandrinos: hizo el "Retrato" ("Mi infancia son recuerdos de un patio de Sevilla...") en cuartetas $A B A B$, con los versos $B$ llanos, pero prefirió los pareados. El poema "A la muerte de Rubén Darío" es un romance alejandrino (asonancia $a)^{68}$; y sólo uno de sus sonetos está en alejandrinos (el dedicado a Valle-Inclán).

66 Dávalos tiene también unas coplas manriqueñas dedicadas a Campoamor, y una rara declaración de amor a don Justo Sierra ("ya ministro [de Educación]") en que, al lado del Batilo de Anacreonte y el Alexis de Virgilio, aparece el Lord Douglas de Oscar Wilde (p. 117). Deja la impresión de querer a toda costa estar al día. ¿Causa sensación el alejandrino? Él escribe alejandrinos. ¿Causa sensación el espiritismo? Él dirige tres sonetos "A una espírita”. ¿Está de moda escribir Phriné, Herakles y Athenea? Él se atreve a escribir Psykhis (ni siquiera Psychê). Es significativo que el poema final de Las ofrendas sea un romance que se intitula - y comienza- "Mis versos van siendo viejos...".

67 Estos "super-alejandrinos" ya habían sido empleados por Díaz Mirón (díptico sonetil "La giganta"), y se hallan también en Lugones ("Ofrenda") y en Sara de Ibáñez ("Por las puntas de mis nervios gotean las golondrinas...").

68 "Del campo", de Rubén Darío, es también un romance en alejandrinos (asonancia á). Ya lo había hecho Zorrilla, "Colón” (asonancia é). 
1875] José Santos Chocano (Alma América, Madrid, 1906) tiene buen número de poesías en versos alejandrinos (de hemistiquios siempre muy bien marcados): 29 sonetos, 15 de ellos $A B A B-A B A B-C C D-E E D$, con $B$ y $D$ agudos; 10 poemas estróficos, 8 de ellos con la consabida alternancia de rimas llanas y agudas, y 13 poemas en pareados, algunos bastante largos. (Además, pp. 320 y 334, dos poemas en pareados, pero con versos de 17 sílabas: $7+5+5$. $)^{69}$

1888] Ramón López Velarde (Obras, ed. J. L. Martínez, 2a ed., México, 1990) emplea los alejandrinos con relativa frecuencia. Casi todos son ortodoxos: por eso llaman la atención atrevimientos como "Dime, plaza de nidos $\mid$ musicales, de làs / actrices que...", "pero atinaban còn | el mundo elemental", "Hoy, como nunca, me èna|moras y me entristeces", y "Piano llorón de Gèno|veva, doliente piano".

1889] Alfonso Reyes (Constancia poética, 1959, t. 10 de las Obras completas) no se apartaría mayormente de sus contemporáneos en cuanto al uso del alejandrino - 16 sonetos, 12 poemas estróficos, 6 en pareados- de no ser porque, siguiendo el ejemplo de Lugones en sus fragmentos homéricos, tradujo en alejandrinos rimados los libros I-IX de la Ilíada (Primera [y única] parte, Aquiles agraviado). Nunca practica los "descoyuntamientos".

1892] César Vallejo (Poesías completas, ed. César Miró, Buenos Aires, 1949) radicalizó su métrica con rapidez notable. En Los heraldos negros, de 1918, hay todavía, como en homenaje a Darío, sonetos de alejandrinos con rimas llanas y agudas (típico: "Por los cuadros de santos en el muro colgados / mis pupilas arrastran un jay! de anochecer..."); la única excepción es "El poeta a su amada", sin agudos. Hay agudos también en los versos pares de varios poemas estróficos. Pero al mismo tiempo hay atentados muy graves contra el alejandrino y contra el soneto: por una parte, versos descoyuntados como "de la alondra que sè | pudre en mi corazón”, "mucho a la mesa, còn | la amargura de un niño", etc., y aun "Son las ocho de là ma|ñana de un cielo brujo", "ante mis mayos dèsar|mados de juventud" y "las

69 El "modernismo" de Chocano es muy parcial, lo cual se debe a que no tiene nada de afrancesado. Quizá ni sabía francés. Él reparte sus amores entre América y España. Alma América se inicia con una cartita de Menéndez Pelayo, un prólogo de Unamuno y un "Preludio" de Rubén Darío (en alejandrinos pareados). Las viñetas son de Juan Gris, cosa que no se hace notar en la portada, quizá por tratarse de un principiante. 
dos lenguas de sùs senos [¡esdrújulo!] | abrasadas de sed”; y, por otra parte, un soneto francamente polimétrico, "Idilio muerto", que intercala en los alejandrinos un endecasílabo y tres heptasílabos. (Esta polimetría es frecuente en los poemas estróficos.) En Trilce (de 1922) y en los poemas posteriores, las dos tendencias se exacerban. Salta a la vista en Vallejo una como voluntad de destruir regularidades.

1893] Jorge Guillén (Cántico, ed. de México, 1945; Homenaje, Milán, 1967; Y otros poemas, Buenos Aires, 1973). En los tres libros abundan los alejandrinos, pero sin rimas, o sea sueltos. En Cántico no hay un solo poema alejandrino rimado; en Homenaje hay buen número de sonetos, estrofas de cuatro versos y pareados; en $Y$ otros poemas no encuentro sino tres sonetos en alejandrinos.

1899] Jorge Luis Borges (Obra poética, 7a ed., Buenos Aires, 1967) no es muy afecto al alejandrino. En Luna de enfrente (1925) hay una poesía intitulada "Versos de catorce": estrofas de alejandrinos, pero con rimas asonantes, lo mismo que "Al horizonte de un suburbio" y "El general Quiroga va en coche al muere" (y "Fundación mítica de Buenos Aires", en Cuaderno San Martín, 1929). En los poemas posteriores se decide Borges por las estrofas aconsonantadas ("La noche cíclica", "Poema del cuarto elemento", "Al vino", "El hambre"). Su único soneto en alejandrinos, "Soneto del vino", es de hechura anómala: $A B A B-C D C D-E F F-E G G$.

1899] Arqueles Vela (El sendero gris y otros poemas, México, ca. 1920), uno de los corifeos del curioso "estridentismo" mexicano (mucha estridencia y pocas nueces), abomina de cuanto huela a modernismo; algunos de sus 18 sonetos son casi alejandrinos, pero en general son decididamente anárquicos, un poco como los del Vallejo tardío.

1902] Jaime Torres Bodet, en Poesía I (México, 1998), tiene 17 sonetos, ocho de ellos en alejandrinos; también dos poemas largos en dísticos (pp. 105-108 y 146-150).

1903] Jorge Cuesta (Poemas y ensayos, México, 1964) es autor de un solo soneto en alejandrinos (traducción del célebre de Mallarmé, "Tel qu'en lui-même enfin l'éternité le change...") y de un breve poema en versos sueltos.

1904] Salvador Novo (Poesía 1915-1955, México, 1955) emplea alejandrinos únicamente en los Poemas de adolescencia (1918-1923): nueve poesías estróficas (como "El loco”), cuatro sonetos, un poema en pareados ("La parábola del hermano") y 
no mucho más. Practica moderadamente el descoyuntamiento: "y eres ultraterrena|mente buena y divina", "pero dudé como èl | marqués de Bradomín”, "en imposible evò|cación de la mañana”...

1910?] Sara de Ibáñez (Las estaciones y otros poemas, México, 1957): su gran "Canto a Montevideo" está hecho en tercetos de alejandrinos, con el encadenamiento y los consonantes ortodoxos; pero en sus poemas estróficos usa sólo la asonancia (como para evitar el énfasis).

1914] Octavio Paz (Obra poética, México, 1990) tiene sólo dos poemas en alejandrinos: uno juvenil (segunda sección de "Noche de resurrecciones", 1939) y otro de la edad madura ("Epitafio sobre ninguna piedra", publicado en Árbol adentro, 1976-1988); el primero está en tercetos con los versos 1 y 3 asonantados y el 2 suelto; el otro - "Mixcoac fue mi pueblo: tres sílabas nocturnas..."- consta de sólo cinco alejandrinos, sueltos, pero de hechura rubeniana o juanramoniana (incluyendo el v. 5: "Mi casa fueron mìs pa|labras, mi tumba el aire"). Se diría que el recuerdo de la infancia se trabó aquí con el de las primeras lecturas de poetas.

1926] Tomás Segovia no suele emplear el alejandrino como metro "autónomo"70, pero sí, y mucho, como componente de silvas polimétricas. Por ejemplo:

La ciudad amanece entre los brazos de la niebla apenas insinúa en un difuso ahogo

el día su remota fuerza

duerme aún entre rocas de pálidas caricias [...]

o se queda en suspenso absorta en brumas

dichosa de su errancia...

Siempre números impares de sílabas: versos de 7, 9, 11 y 13 sílabas; y también alejandrinos, que equivalen a $7+7$. Expreso o subyacente, hay ese ritmo yámbico al cual ha tendido desde siempre la poesía española de ascendencia italiana: "el agua baña el prádo con sonído...", "luciénte honór del ciélo, / en cám-

70 Salvo en Bisutería (1981), donde reúne un puñado de divertissements y versos de circunstancia en alejandrinos; casi todos están en pareados, pero hay una breve "Carta culta" dirigida a Antonio Alatorre en cuaderna vía (y en fabla de Berceo). Lo mismo - tres estrofas de cuaderna vía y fabla - había hecho Rubén Darío, "La poesía castellana”, II; y lo mismo, pero sin fabla, hizo Alfonso Reyes, "A Agustín Millares Carlo”. 
pos de zafíro páce estréllas". La canción y la silva se armaron siempre con versos de 11 y 7 sílabas, pero ya López Maldonado (1586) y Espinel (1591), en sendas canciones, habían incorporado el verso de 5; Góngora incorporó el alejandrino y Lista el eneasílabo, de manera que estaba la puerta abierta para acoger también versos de 13 y 15 sílabas. La silva polimétrica no es, por supuesto, invento de Segovia ${ }^{71}$, pero él la ha puesto muy en alto, no sólo por haberla hecho vehículo de dos poemas de gran aliento - Anagnórisis (1965-1967) y Cantata a solas (1983) -, sino también por haber trabado muy orgánicamente el discurso con esa polimetría, en la cual imperan el heptasílabo, el endecasílabo y el alejandrino ${ }^{72}$.

1939] José Emilio Pacheco no se sirve de los alejandrinos - ortodoxos, y además rimados- sino para traducir a Nerval, Rimbaud, Mallarmé y Baudelaire (versiones incluidas en Tarde o temprano, 1980).

El caso de Pacheco nos retrotrae a la profecía que Henríquez Ureña hizo en 1946 ( supra, nota 6): el alejandrino "bien podría eclipsarse de nuevo", tal como estuvo tranquilamente eclipsado durante siglos. Los alejandrinos "autónomos" se van haciendo raros; los de Pacheco no son espontáneos, sino forzados (por así decir). Pero el caso de Segovia nos invita a modificar la profecía: eclipse, sí, pero parcial. No volverá a haber ni un Berceo ni un Trigueros ${ }^{73}$, pero sí poetas como Segovia, que escribe en

${ }^{71}$ Baste recordar a Rubén Darío, "Helios" (versos de 7, 11 y 14), "Como al fletar mi barca con destino a Citeres..." (alejandrinos, pero con un verso de 7 y dos de 9 sílabas), "Mar maravilloso..." (versos de 5, 7, 11 y alejandrinos ). Más ejemplos: “¡Ganivet! ¡Ganivet!”, “¡Corre, Atalanta, corre!” y "Carne, celeste carne...”.

72 Cantata a solas (México, 1985) ofrece en las pp. 87-89 una "Guía prosódica" que a muchos les convendría leer. Se lee ahí: "En este y otros libros del autor [como Anagnórisis], la supresión de la puntuación obedece a una tentativa de articular la configuración prosódica del verso con la de la sintaxis «prosaica» (o «normal») con tanto rigor por lo menos como el que puede alcanzar su transcripción en una grafía con signos de puntuación”. Basta leer los versos que he citado (y que son el comienzo de Anagnórisis) para comprobar que el discurso poético es, gracias a la polimetría, capaz de hacer superflua la puntuación.

${ }^{73}$ Dice Chesterton no recuerdo dónde que a la humanidad le encanta el juego de la profecía. Siempre surgen profetas; los oímos con mucho interés; un día se mueren; los enterramos solemnemente; regresamos a casa y nos ponemos a hacer lo contrario de lo que ellos profetizaban. 
verso libre como muchos otros modernos -adiós rimas, adiós uniformidad métrica, adiós disposición en estrofas, etc.-, pero que no confunde la libertad con la irresponsabilidad o la anarquía. Y es que la poesía es un arte emparentado desde siempre con la música (la melodía, el ritmo). El verso libre debe seguir siendo verso, no prosa partida en líneas irregulares.

Una cosa es clara: el alejandrino está como opacado por el octosílabo, metro ibérico por excelencia, y por el endecasílabo, italiano por excelencia. Se hacen hoy octosílabos como los del romancero viejo y endecasílabos como los de Boscán y Garcilaso. No ha habido eclipse alguno. A pesar de que las innovaciones métricas no se generalizan así como así, y nunca faltan los condenadores de lo "extranjero", lo "ajeno a nuestra herencia cultural”, el endecasílabo se aclimató con extraordinaria prontitud, mientras que el alejandrino no ha perdido del todo su aire "exótico", y desde los tiempos de Trigueros hasta los nuestros ha habido buen número de no-aceptadores y de francos opositores.

Argote de Molina, el primer crítico que se ocupó de estos versos, comprende que hayan gustado en la Edad Media, pues su "lerdez y espacio" van bien con la pachorra de esos tiempos; pero los poetas de ahora, como son "algo coléricos", encuentran "muy flegmática y de poco donayre y arte" semejante compostura. Para Carvallo, el del Cisne de Apolo, el alejandrino es una curiosidad, una rareza: verso larguísimo, pie que calza 14 puntos. El soneto de Pedro Espinosa sobresale justamente por ser una rareza. Y no habiendo ya alejandrinos, puede Trigueros alardear de ser padre de un metro nuevo, al cual, como a criatura recién nacida, bautiza con el nombre de "pentámetro", calificándolo de armonioso y de magestuoso. De hecho, sus alejandrinos se caracterizan más por lo segundo que por lo primero: él engola la voz, así en la solemne invocación ("Dime, sublime Pope, tú, reflexivo genio...") como en la ardiente perorata (“¿Qué sirve a Dios ni al mundo quien no sirve de nada?”).

A causa de este carácter majestuoso, pudo haber habido una gran epopeya en alejandrinos. El humanista Agustín de Castro, uno de los jesuitas expulsados de México en 1767, quiso dedicar los ocios del destierro a la ejecución de una idea que acariciaba desde joven: un gran poema sobre Hernán Cortés. ¿Qué metro elegir? Había tres posibilidades: octavas reales, silva, y alejandrinos. El metro obvio serían las octavas (las de Tasso y Camoens y Ercilla), pero él las sentía demasiado metódicas 
o encajonadas. El de silva sería mejor, ¡lástima no poder extender los versos más allá de las once sílabas! La lectura de las Poesías filosóficas debe de haberlo impresionado; y en alejandrinos hubiera escrito su Cortesíada si no lo hubiera arredrado, a última hora, la monotonía de los alejandrinos de Trigueros ${ }^{74}$.

El alejandrino de Zorrilla es tan majestuoso como armonioso, y se explica su poder de seducción hasta en pleno modernismo. Pero ya en 1866 José Coll y Vehí le pone peros. Desde luego, es "materialmente imposible" evitar la monotonía que causa la lectura de Berceo o del Alexandre. En pequeñas dosis está bien: ahí tenemos a Zorrilla. Pero Zorrilla mismo no se salva de la monotonía. "Dentro del acompasado ritmo de los versos alejandrinos, la fantasía, como el ave encerrada en doradas rejas, no puede tender el vuelo por los espacios umbríos de la floresta...; la monotonía del ritmo parece como que se pega al pensamiento y lo esclaviza". Los versos de Zorrilla son "magníficos", sí, pero a menudo es la magnificencia lo que sale sobrando. Coll y Vehí encuentra mejor "Granada" que las pomposas Nubes, y su poema predilecto es "La nube de verano" de José Selgas, hecho en estrofas zorrillescas pero sin ninguna pretensión de magnificencia ${ }^{75}$. No le faltaba razón. Lo "majestuoso" no era buen camino. El tono de la poesía de Selgas hace pensar ya en el de las Rimas de Bécquer, donde Zorrilla está completamente borrado. Por algo Bécquer, que empleó buena cantidad de metros, no hizo nada en alejandrinos.

Ese trasfondo gris ${ }^{76}$ (o francamente negro: Menéndez Pelayo) ayuda a ver en todo su esplendor el triunfo modernista del

74 Véase Juan Luis Maneiro, Vidas de mexicanos ilustres, trad. B. Navarro, México, 1956, pp. 70-71. El P. Castro pensó también en los hexámetros, pues le gustaban las adaptaciones de Esteban Manuel de Villegas que había leído en México, y hasta tradujo en hexámetros castellanos la Égloga I de Virgilio, para ejercitar la mano. Pero al fin se decidió por la silva. (Las poesías del P. Castro están perdidas.) Curiosamente, también Gavidia, después de traducir a Hugo en alejandrinos, quiso subir más alto y escribió en hexámetros (no muy convincentes) su extravagante canto épico Los aeronautas, en celebración de Santos Dumont.

75 José Coll y Vehí, Diálogos literarios. (Retórica y poética), $3^{\text {a }}$ ed., Barcelona, 1885, pp. 374-378. (Esta edición lleva un prólogo de Menéndez Pelayo.)

${ }^{76}$ Para Teodoro Llorente, traductor del Fausto de Goethe, el alejandrino no era "metro adecuado a nuestro idioma"; por eso no pensó en él cuando se disponía a traducir los Triomphes de Hérédia; y, como hubiera sido tarea sobrehumana comprimir en once sílabas lo que Hérédia decía en catorce, optó por no traducirlo. 
alejandrino en los últimos años del siglo xIx y primeros del xx. Jesús Valenzuela, en el ya mencionado poema dedicado "A Leopoldo Lugones, en París", entona un himno al seductor metro llegado de Francia:

¡Oh Verso Alejandrino! a quien preceden pajes, príncipes y princesas - sedas, oro, encajes-.

¡Oh Verso Rey! que moras en palacios de Francia, a quien en copa heroica el rojo vino escancia

de su sangre la Musa...

Y tres años después se imprime (en París) la gran apoteosis del soneto alejandrino modernista: Las sombras de Hellas de Leopoldo Díaz.

Esto no duró. Significativamente, la fiebre alejandrina de Juan Ramón Jiménez no duró sino cinco o seis años (de 1907 a 1912). Sin embargo, el alejandrino sobrevive, y no sólo en casos como los de Segovia y Pacheco. Testigo la Ilíada de Alfonso Reyes, poeta de buen oído. El alejandrino no está muerto ${ }^{77}$.

\section{APÉNDICE SOBRE TIPOGRAFÍA}

Al comienzo de este artículo digo que los Proverbios de Sem Tob pueden leerse indiferentemente como alejandrinos de rima interna y como parejas de heptasílabos, y aquí y allá señalo otros casos de correspondencia o falta de correspondencia entre los versos y su tipografía, por ejemplo los alejandrinos de Góngora, disfrazados de heptasílabos. Recojo aquí otros ejemplos de lo mismo. Y sea el primero el "Nocturno" de Manuel José Othón, donde hay algo parecido a lo que ocurre en la canción "Vuelas, oh tortolilla". El "Nocturno" está hecho en estrofas de seis versos, así:

77 El mexicano Ambrosio Ramírez (1859-1913), buen traductor de Horacio, procura siempre que sus estrofas se parezcan a las horacianas; y para traducir el Solvitur acris (I, 4), donde se emplea el larguísimo verso arquiloquio, elige acertadamente el alejandrino. Lo malo es que se meten los agudos zorrillescos, que no van bien con Horacio. 
Sin una sola lágrima que tiemble en la pupila

y pueda los dolores decir del corazón, a ti me acerco, y mi alma que lágrimas destila

implora de tus ojos la ráfaga tranquila que calme lo infinito de su febril pasión.

El verso 3, heptasílabo suelto, es en realidad primer hemistiquio de un alejandrino, y la estrofa no es sino la muy conocida de cinco versos $A B A A B$, con el $B$ zorrillescamente agudo. Othón hizo esto adrede: es obvio que quiso aligerar la estrofa, hacerla más atractiva a simple vista para el lector. Pablo Neruda lleva esto al extremo en esos poemas escritos no para los exigentes, sino para "el pueblo": fragmenta los versos largos como quien parte el pan para un pequeñín, y se las arregla para que alejandrinos como estos tres de la "Oda al tomate":

...Debemos, por desgracia, asesinarlo: se hunde

el cuchillo en su pulpa viviente; es una roja

víscera, un sol franco, profundo, inagotable

se conviertan en once versos chiquitos.

En fin, cada poeta sabrá lo que hace cuando elige una cosa o la otra. Rubén Darío se decide por los versos cortos en "Alegoría":

En océano férvido

boga débil barquilla, partiendo la ola indómita con su afilada quilla...

Son estrofas de doce heptasílabos, con los versos impares terminados siempre en voz esdrújula. Lo que ocasionalmente ocurre en versos de la "Sonatina" como "piensa acaso en el príncipe de Golconda o de China”, aquí Darío lo hace sistemáticamente: "En océano férvido boga débil barquilla...", etc., y para mejor lucir esta esdrujulez separa el primer hemistiquio del segundo. Algo parecido hace Tablada en su soneto "La conga", donde los alejandrinos se parten en dos y producen una canción "tropical" que no parece tener nada de alejandrino (ni de soneto):

La mulata de ébano

mece en una canción

como en fácil hamaca

su candor animal... 
También se hace lo contrario: versos cortos con apariencia de largos. Manuel Larrañaga Portugal, uno de los poetas de la Revista Azul, hizo un poema en alejandrinos terminados todos con un solo asonante, de manera que es en realidad un romancillo heptasílabo. (Caso parecido al de "La caja de pasas" de Salvador Rueda: cf. NAVARRo, § 400, nota.)

He dicho -y lo repito aquí- que me gusta leer los romances en octosílabos y no en engorrosos dieciseisílabos. Mi postura se parece a la de Gonzalo Correas cuando habla en su Arte de las dos posibles presentaciones "tipográficas" de las seguidillas: quienes las escriben en dos versos largos le merecen respeto, pero a él le gustan mejor en cuatro versos $\operatorname{cortos}^{78}$. Muchos preferían los largos: así están escritas, por ejemplo, las seguidillas de los Romancerillos de Pisa publicados en RHi, 65 (1925), pp. 160 ss. Y no hay que olvidar las seguidillas de Góngora presentadas en versos largos: "Mátanme los celos de aquel andaluz..."79. Seguramente la preferencia de Correas era compartida por muchos, puesto que hoy las seguidillas se escriben siempre en cuatro "versillos". Rubén Darío puede llevar la contra y hacer seguidillas en versos largos. En "A una amiga" las seguidillas tienen su forma "normal" ("No de recuerdo ingrato / lleves la huella...."), pero en "Cantilena" se disfrazan de dodecasílabos ("Virgen ardiente y pura de Nicaragua..."). Tal parece que al escribir seguidillas en versos largos les confería una especie de "dignidad" y las apartaba de lo populachero. Por algo su "Elogio de la seguidilla" no está escrito en seguidillas, sino en versos solemnes: "Metro mágico y rico que al alma expresas...". (De hecho, los "dodecasílabos de seguidilla”, practicados asimismo por Salvador Rueda y otros, están ya en el "Álbum de un loco" de Zorrilla.)

Antonio Alatorre

El Colegio de México

78 "Casi todos escriven las seghidillas en dos versos, que viene a ser cada uno de onze o doze sílabas: i no van fuera de comodidad, como [=con tal que] adviertan y entiendan que en la sesta o sétima sílaba se an de partir i acabar dición... Io tengo por cosa más propia i clara escrivirlos en sus cuatro versillos, con que se conozcan mexor sus quiebros y partición”.

${ }^{79}$ Sor Juana suele usar seguidillas como estribillo, y las hace en versos largos: "A la fiesta del cielo, las voces claras / una reina celebran pura y sin falta"; "Oigan, oigan, deprendan versos latinos, / porque Pedro los tiene muy bien medidos" (Obras, ed. Méndez Plancarte, t. 2, pp. 18 y 50), etc. 